Anuario de Historia Regional y de las Fronteras, Vol. 23 No. 2 DOI: http://dx.doi.org/10.18273/revanu.v23n2-2018008 (c) (i)

\title{
Aproximación al barrio Policarpa Salavarrieta por medio de la organización social CENAPROV (Bogotá), 1961-1970*
}

\section{Resumen}

El artículo analiza la experiencia entre los años 1961 a 1970 del barrio Policarpa Salavarrieta, el cual está ubicado en la ciudad de Bogotá y es emblemático en las luchas por la vivienda digna que impulso la Central Nacional Provivienda. Su estudio nos permite analizar el nacimiento del movimiento por la vivienda en Colombia y reconstruir la parte inicial de su historia. La violencia desarrollada en la década de 1950 en las zonas rurales, así como la exclusión, la pobreza y las precarias condiciones en diferentes departamentos, fueron las causas de esta migración hacia las principales ciudades del país, donde la absorción de esa población desplazada la hizo en gran medida la ciudad de Bogotá. A partir de esta hipótesis, el texto se ubica dentro de la historia social y barrial con una perspectiva local y regional, el cual expone resultados cualitativos y cuantitativos para dar finalmente una comparación entre ambos y así realizar un acercamiento más confiable a este movimiento social representado en la sociedad colombiana.

\section{Palabras clave}

Tesauro: vivienda, movimiento social, tierra agrícola, historia, exclusión social.

Referencia para citar este artículo: Sánchez Triviño, Leandro Andrés. “Aproximación al barrio Policarpa Salavarrieta por medio de la organización social CENAPROV (Bogotá), 1961-1970”. Anuario de Historia Regional y de las Fronteras 23.2 (2018): 223-256. DOI: 10.18273/revanu.v23n2-2018008

Fecha de recepción: 10/01/2017

Fecha de aceptación: 18/04/2018

Leandro Andrés Sánchez Triviño: magíster en Historia y licenciado en Ciencias Sociales, Universidad Pedagógica y Tecnológica de Colombia (UPTC), Colombia. Docente internacional en American International Academy: Weifang, China. Coordinador estrategia Gobiernos Zonales, Alcaldía Mayor de Bogotá, gestor de políticas públicas, Colombia. Código ORCID: https://orcid.org/0000-0002-8975-5826. Correo electrónico: filosofialast@hotmail.com.

\footnotetext{
"En este artículo se presentan datos y resultados obtenidos en la investigación histórica y barrial "Cenaprov y la construcción de barrios en Bogotá de 1959 a 1979: los casos de Policarpa Salavarrieta y Julio Rincón”, Bogotá, Colombia, sin ninguna financiación y corresponde a la tesis de maestría del autor en la Universidad Pedagógica y Tecnológica de Colombia (UPTC), Colombia.
} 


\title{
Approach to the Policarpa Salavarrieta Neighborhood Through a Social Organization: CENAPROV (Bogotá), 1961-1970
}

\begin{abstract}
This article analyzes the experience of the "Policarpa Salavarrieta" neighborhood between 1961 and 1970, which is located in the city of Bogotá and is emblematic in the struggles for decent housing promoted by the "Central Nacional Provivienda". Its study allows us to analyze the birth of the housing movement in Colombia and reconstruct the initial part of its history. The violence developed in the 1950s' rural areas, as well as the exclusion, poverty and precarious conditions in different departments, were the causes of the migration to the main cities of the country, where the absorption of this displaced population was largely done by the city of Bogota. Starting from this hypothesis, the text is located within the social and neighborhood history with a local and regional perspective, which exposes qualitative and quantitative results to finally give a comparison between both, and thus making a more reliable approach to this social movement represented in Colombian society.
\end{abstract}

Keywords

Thesaurus: Living Place, Social Movement, Agricultural Land, History, Social Exclusion.

\section{Abordagem ao bairro Policarpa Salavarrieta através da organização social CENAPROV (Bogotá), 1961-1970}

\begin{abstract}
Resumo
O artigo analisa a experiência do Bairro Policarpa Salavarrieta nos anos 1961-1970, que está localizado na cidade de Bogotá e é emblemático nas lutas pela moradia digna para impulsionar a Central Nacional Provivienda. Seu estudo nos permite analisar o nascimento do movimento para habitação na Colômbia e reconstruir a parte inicial de sua história. A violência desenvolvida na década de 50 em áreas rurais, assim como a exclusão, pobreza e condições precárias em diferentes departamentos, foram as causas desta migração para as grandes cidades, onde a absorção da população deslocada foi em grande medida feita pela cidade de Bogotá. Com base nesta hipótese, o texto é localizado dentro da história social e do bairro com uma perspectiva local e regional, que apresenta resultados qualitativos e quantitativos para finalmente fazer uma comparação entre eles. Portanto, apresentando uma abordagem mais confiável para este movimento social representado na sociedade colombiana.
\end{abstract}

Palavras-chave

Thesaurus: habitação, movimento social, terras agrícolas, história, exclusão social. 


\section{Introducción}

Con la fundación del barrio Policarpa Salavarrieta se desarrollaron procesos de toma de tierra de los cuales se tienen antecedentes importantes, algunos líderes sociales y políticos a favor del derecho a la vivienda dirigieron procesos en el Valle del Cauca y en Cali a finales del año 1944, procesos que se materializaron de una forma organizada, ya que todas las ocupaciones de terrenos ejidos u ociosos se dieron por organizaciones de inquilinos que existían desde 1920, las cuales se articularían fácilmente a Cenaprov. Para 1959 se funda en Bogotá la Central Nacional Provivienda, CENAPROV, con la intención de solucionar el problema de la falta de vivienda para cientos de familias vulnerables de una forma organizada y con planificación previa. ${ }^{1}$ Teniendo en cuenta lo anterior, el presente artículo plantea la importancia del barrio Policarpa Salavarrieta, ya que en él se tejieron las nuevas condiciones favorables no solo de colonizar un territorio para vivir, sino además de ello, las familias se organizaron alrededor de dicho territorio generando procesos de movilización, formación y asociación; lo que resultó en el nacimiento de un movimiento social, que fortaleció la organización y finalmente garantizó el asentamiento definitivo en el territorio. El origen del barrio Policarpa Salavarrieta se da con la ocupación de un terreno ocioso en el centro de la capital del país en 1961 y 1962. Las iniciativas de articulación social y solidaridad comunal dieron las condiciones para fundar el barrio, donde a través de la orientación de los líderes de la naciente Cenaprov se logró consolidar el movimiento por la vivienda. Los resultados organizativos que fueron producto del crecimiento del barrio en materia social permitieron su surgimiento, ya que los procesos de toma, constitución y fundación del barrio fueron el eje que consolidó y expandió la organización en pro de la vivienda para cientos de familias vulnerables; la expansión fue rápida y se fundaron decenas de barrios por autoconstrucción, no solo en Bogotá o Cundinamarca, sino para finales de la década de 1970, Cenaprov ya tenía presencia en 120 municipios del país. $^{2}$ El artículo se centra en la experiencia del Barrio Policarpa, en relación con la consolidación de la organización en Bogotá.

Se presentan además los resultados de una investigación de maestría en historia, ubicada metodológicamente en la historia social y barrial, la cual se realizó con enfoque cualitativo y cuantitativo, valiéndose en un primer momento del análisis documental a partir de 98 fuentes seriadas revisadas sistemáticamente: documentos normativos oficiales, testimonios escritos, informes de asambleas, informes de tesorería sobre gastos de autoconstrucción, cartas y peticiones a entidades estatales. ${ }^{3}$ Después se contrastó la información encontrada con 50 entrevistas a una muestra de habitantes del barrio Policarpa Salavarrieta elegidos con criterios de relación sanguínea con los fundadores o con el proceso de toma y fundación del barrio. La

\footnotetext{
${ }^{1}$ Archivo Histórico de Provivienda, (AHP). Colombia, Fondo Municipios de Provivienda (MP), Sección Actas de Registro, t. 087, f. 23v.

${ }^{2}$ María Elvira Naranjo. "Provivienda: protagonista de la colonización popular en Colombia", Historia y Memoria.9 (2014): 1-31.

${ }^{3}$ AHP, Colombia, Fondo MP, Sección Registro Etapa 01 Cenaprov, t. 092, f. 11v.
} 
investigación expone hallazgos inéditos sobre el tema, se acerca a las técnicas del análisis de contenido de las fuentes secundarias y primarias, con una interpretación de los productos comunicativos como: mensajes, testimonios escritos o discursos, que proceden de procesos singulares de comunicación que previamente fueron registrados en documentos, los cuales guiaron a la presente investigación en la combinación de categorías donde se procesaron los datos relevantes sobre las condiciones mismas en las que fueron producidos aquellos textos. La postura interpretativa se da desde el campo histórico y político, se proponen acercamientos descriptivos y explicativos de los temas analizados y se compararon de una manera crítica con las diferentes fuentes encontradas, con el objetivo de lograr un grado de confianza en los resultados e interpretaciones plasmadas en este artículo. La muestra fue tomada de la manzana más antigua del barrio, la manzana de los fundadores, siendo esta la primera fracción de tierra ganada por este movimiento social en 1961. ${ }^{4}$ La unidad de análisis elegida fue el centro de inquilinos, su importancia es vital como la primera forma de asociación de Cenaprov. ${ }^{5}$ Por medio de una caracterización de esta población identificada en dicho proceso, se pasó a indagar con entrevistas tres aspectos fundamentales: su lugar de procedencia, sus razones para llegar al proceso de toma de tierra en la capital del país y su rol específico en el movimiento pro vivienda.

El artículo tiene una estructura planificada, en un primer momento se hizo el acercamiento a referentes teóricos, donde se presentó el debate historiográfico que sirvió para analizar su relación con la investigación y así apoyar los planteamientos de la misma. En un segundo momento, se realizó el análisis documental de las fuentes primarias y secundarias contrastándolo con 50 entrevistas, las cuales fueron hechas a personas pertenecientes a las familias de los fundadores. Después se hizo la comparación, por un lado, de los resultados cualitativos obtenidos por la revisión sistemática de documentos, testimonios escritos y entrevistas, en contraste con todas las mediciones y resultados estadísticos sobre las mismas preguntas, pero esta vez desde un enfoque cuantitativo. La parte final corresponde al análisis crítico de las estadísticas demográficas del censo realizado por el Centro de Estudios Demográficos de la Universidad Nacional y la Asociación Colombiana de Facultades de Medicina, a quienes se les encomendó su realización en $1967 .{ }^{6}$ Ellos elaboraron un cuestionario que respondieron 500 familias que correspondían al 98\% de la población del barrio para 1967, en el cuestionario se incluían preguntas relacionadas con variables de tipo demográfico que fueron utilizadas en esta investigación para caracterizar la

\footnotetext{
${ }^{4}$ Archivo Acción Comunal Distrital, (AACD), Colombia, Fondo Policarpa Salavarrieta (PS), Sección actas de Registro. t. 191, f. 250v.

${ }^{5}$ Archivo AHP, Colombia, Fondo MP, Sección Registro Etapa 01 Cenaprov, t. 094, f. 21v.

${ }^{6}$ El Viernes Santo de 1966, a doce cuadras de la plaza de Bolívar y a 14 del Palacio Presidencial, elementos de la Policía Nacional se enfrentaban en ardorosa lucha contra 500 familias. El motivo de la contienda era el intento policial de erradicar la población que había invadido terrenos pertenecientes al Instituto de Crédito Territorial. Un año después, cuando estas familias se habían consolidado y arraigado en este predio al que llamaron barrio Policarpa Salavarrieta, se levantó un censo de su población con el objeto de orientar unas negociaciones con sus líderes. El fin de las negociaciones era reubicar a las familias y conocer las posibilidades de que en dicho terreno se construyera un Centro de Salud destinado a convertirse en el más importante de Colombia. Véase: Ramiro Cardona, "Estudio de un Barrio de Invasión", Revista de la Universidad Social católica de la Salle 1.1 Universidad Católica (1967): 1-20.
} 
población identificada con los procesos de toma y fundación del Policarpa. A su vez el cuestionario planteaba otras preguntas que le interesaban en ese momento a la Universidad Nacional, como lo eran: lugar de procedencia, tipo de residencia en que vivió por primera vez cuando llegó a Bogotá, número de personas que forman la familia e ingreso mensual de la familia. Los resultados de este censo demográfico y socioeconómico sobre el barrio Policarpa Salavarrieta en 1966 se interrelacionan con las preguntas de esta investigación y ayudaron a dar validez científica desde un enfoque cuantitativo al presente artículo. Al contrastar toda esta información se presentaron los resultados y las conclusiones, planteando la importancia de la reflexión histórica sobre este proceso social y barrial.

\section{Referentes teóricos, causas del desplazamiento y movimiento por la vivienda en Colombia}

En esta sección del artículo se analiza el contexto político y económico, las causas del desplazamiento y el movimiento social por la vivienda en Colombia. El movimiento social está ligado teóricamente a la categoría de clase, pero se mantiene distanciado de la perspectiva de lucha de clases como un eje central para su análisis. Reflexionando sobre las conceptualizaciones de los movimientos sociales como la disputa en torno a un conflicto central de la sociedad, definido como una lucha simbólica y cultural, se puede afirmar que esta categoría de análisis sigue quedando anclada. Solo algunas manifestaciones de la acción colectiva avanzan en la interpretación de múltiples procesos que tienen naturalezas distintas, entendiendo que no se trata simplemente de luchas por el poder político, ni por intereses específicos, sino en este caso en particular es la disputa alrededor de un conflicto central de la sociedad, que se expresó a través de las familias sin tierra. Por otra parte, cobra relevancia entender desde un concepto analítico a los movimientos sociales, no solo como actores o fenómenos colectivos, sino como una dimensión analítica la cual se manifiesta en los escenarios sociales y puede estar presente en cualquier proceso de acción o de identidad colectiva, manteniendo la constante de disputa frente a un conflicto central de la sociedad. Para el caso colombiano, la acumulación excesiva de tierra especialmente rural, y el control sistemático sobre la misma por parte de un grupo privilegiado desencadeno un conflicto de repercusiones inmensas.

El conflicto rural se expresó en violencia política, la cual expulso población rural masivamente e inicio un periodo de inestabilidad política extendida, este escenario tuvo su origen en los conflictos por tierras entre campesinos colonos y latifundistas, problemática que empezó a finales del siglo XIX en la región central de Colombia. Es importante aclarar que la violencia fue el método de apropiación de tierra por parte de latifundistas que desencadeno la reconfiguración de nuevos dueños, los cuales se impusieron en las zonas colonizadas anteriormente por campesinos. ${ }^{7}$ Sumado a esto, los partidos tradicionales dividieron al campesinado forzándolos a tomar un bando, el Partido Liberal o el Partido Conservador, generando disputas territoriales entre

\footnotetext{
${ }^{7}$ Jacques Aprile-Gniset y Gilma Mosquera, "Dos ensayos sobre la ciudad colombiana", Notas sobre el urbanismo de colonización agraria 1.3 Universidad del Valle (1978): 173.
} 
el campesinado en general. El control político de estos dos partidos se expresó con el dominio de zonas rurales, en el cual los campesinos colonos necesitaban de un padrino político para lograr un acuerdo legal sobre las tierras en disputa. Discordia que se daba de varias formas, con vecinos por linderos, colonos tratando de recuperar su tierra o simplemente pugnando por tierras baldías. La rivalidad bipartidista paso por veredas, corregimientos y municipios, generando un conflicto socioeconómico alrededor de la tierra, donde la Iglesia y los latifundistas tuvieron la oportunidad de imponer las condiciones.

No obstante, la crisis económica de fines de los años veinte en Colombia producto de la gran depresión, ${ }^{8}$ tuvo su efecto en el desplome de los intentos modernizadores del presidente Enrique Olaya herrera y de la modernización liberal en general, la cual empezó en 1930 y que represento un proceso fallido que no logro consolidarse. Se amplió la acumulación de tierra en varias regiones del país, gracias al desplazamiento violento de comunidades campesinas, como resultado fue inevitable una confrontación directa, donde buena parte de esa población se dirigió a las ciudades al verse amenazada y vulnerada. por otra parte, el desarrollo de alcantarillados y acueductos desde 1920, el desarrollo que se había logrado en el trasporte terrestre por vía férrea y carretera, la industrialización basada en la sustitución de importaciones y la economía exportadora fueron otros factores que propiciaron el desplazamiento rural y permitieron la acumulación urbana. ${ }^{9}$

El movimiento obrero colombiano representado en sindicatos se llenó de expectativas cuando los liberales llegaron al poder en 1930, pues se ponía fin a décadas de control conservador en el país. La ley 200 de 1936, ley de tierras del presidente Alfonso López Pumarejo que pretendía, entre otras cosas, otorgar tierras a los campesinos que cultivaban terrenos que no les pertenecían, bajo el principio de que la propiedad privada debía cumplir una función social, estuvo acompañada de fuerte oposición, tanto de conservadores como de terratenientes liberales. A pesar de la llamada Revolución en Marcha ${ }^{10} \mathrm{y}$ su intención por involucrar las fuerzas populares y sindicales, solo se limitaron a ganarse el apoyo fragmentado de las centrales obreras para su gobierno. Las huelgas que se daban espontáneamente se normalizaron con un carácter mediador y el intervencionismo estatal fue llevado a cabo por funcionarios que muchas veces dieron la pauta para la negociación con sindicados; fue así como el gobierno liberal apoyo al movimiento sindical por razones principalmente económicas y políticas. Este proceso sagaz del partido liberal aplaco principalmente al movimiento agrario, el cual perdió impulso y alcance político ya que después de cooptado parte del movimiento

\footnotetext{
${ }^{8}$ La crisis económica de 1929 fue la más devastadora caída del mercado de valores en la historia de la Bolsa en Estados Unidos, la crisis se extendió rápidamente por todo el mundo.

${ }^{9}$ Fabio Zambrano, "Más ciudades y más ciudadanos", Revista Semana, publicación online, www.semana. com/wfinfoarticulo.aspxldArt22102, 2002 (20/04/2018).

${ }^{10}$ Revolución en Marcha comprende el período que va desde 1934 a 1938, llamado así para establecer el contraste entre el gobierno de Alfonso López Pumarejo y el de la Concentración Nacional presidido por Enrique Olaya Herrera.
} 
obrero por el liberalismo y sumado a sus filas, las políticas reformistas sobre tierras fueron substituidas por otras que salvaguardaban el statu quo. ${ }^{11}$

La Unión Nacional de Izquierda Revolucionaria UNIR, fue un movimiento de liberales de izquierda que apoyaban las luchas por la tierra emprendida por campesinos colonos y arrendatarios. Ellos popularizaron los derechos contemplados en la legislación agraria, proporcionaron asesoría jurídica demostrando la ilegalidad de los títulos de latifundistas y de hacendados; en términos generales proponían solucionar el problema agrario en dos etapas: reformas de parcelación de tierras con crédito agrario y profundización de las reformas estatales para organizar la economía. Su fundador fue asesinado el 9 de abril de 1948, su nombre Jorge Eliecer Gaitán un importante líder liberal que aspiraba a la presidencia de la república. Esto desencadeno un periodo de violencia más agudo, donde los escenarios fueron las zonas rurales de la región central de Colombia. Finalmente, bajo el marco del autoritarismo conservador de Mariano Ospina Pérez se ejerció control político el cual se expresó en control electoral y se movilizaron grupos de campesinos colombianos entorno a la confrontación violenta. ${ }^{12}$

El Frente Nacional fue la solución política de los partidos tradicionales para lograr la estabilidad política, se alternaron en el poder por 16 años, desde 1958 hasta 1974 y excluyeron a las demás expresiones políticas y sociales. La burocracia y la presidencia de la republica fueron exclusivas de estas dos filiaciones políticas, al cabo de este tiempo no solucionaron la inestabilidad socioeconómica de tierras en el campo y los conflictos violentos continuaron. Las guerrillas campesinas de tendencia comunista enfrentaron a las fuerzas militares hasta mediados de la década de 1960, pedían reivindicaciones políticas, sociales y una reforma agraria generalizada en el país, lucharon contra los terratenientes, latifundistas y grupos armados creados con el fin de erradicarlos. Cuando el ejército y otros grupos contraguerrilleros al margen de la ley lograron destruir a los grupos más notorios de la guerrilla campesina el conflicto cedió, y se interpretó que desaparecerían. Pero en realidad estos grupos campesinos guerrilleros estaban creciendo silenciosamente, y se estaban gestando las condiciones para que se reorganizaran en nuevos grupos armados revolucionarios. ${ }^{13}$

La violencia incremento el proceso migratorio dentro de los departamentos, pero la decisión de migrar a las principales ciudades también tuvo otros factores independientes a la violencia. El proceso acelerado de urbanización no fue únicamente resultado de la violencia política, las causas de la migración también estuvieron impulsadas por el desarrollo económico de las principales ciudades del país. El desarrollo económico tuvo algunos adelantos industriales que atrajeron a la inmensa población rural en búsqueda de opciones de empleo, la urbanización acelerada fue en cierta medida el resultado de la gran pobreza rural, donde esta industrialización incipiente nunca

\footnotetext{
${ }^{11}$ Álvaro Tirado, "Colombia: siglo y medio de bipartidismo", Colombia hoy-Perspectivas hacia el siglo XXI 1.1 (1991): 102-130.

${ }_{12}$ Marco Palacios, Entre la legitimidad y la violencia. Colombia 1875-1994 (Bogotá: Editorial Norma, 1995) 386.

${ }^{13}$ Palacios 234-263.
} 
represento un desarrollo económico a gran escala, pero si se interpretó como símbolo de un buen porvenir. Entre las razones más fuertes del desplazamiento también tenemos las variables económicas, las precarias condiciones de vida en el campo, el desequilibrio en las circunstancias de trabajo en el campo y la quimera de encontrar algo mejor en las ciudades. ${ }^{14}$

Las zonas más atrasadas expulsaron poblaciones campesinas humildes hacia áreas de progreso o polos de desarrollo, los cuales se tradujeron en centros de atracción demográfica. La escasez de servicios públicos e institucionales impulso también esta migración, donde las personas se dirigieron hacia las metrópolis y también hacia grandes centros manufactureros, comerciales, financieros y culturales. ${ }^{15}$ No obstante, las zonas rurales ricas también expulsaron campesinos, pero aquí la violencia si fue protagonista, la región central del país que gozaba de prosperidad agrícola y tenía crecimiento agrario alrededor del café fue un territorio de disputa. Los estudios estadísticos del periodo 1938-1964, demuestran que las áreas de destierro fueron también zonas ya ocupadas, relacionadas con el cultivo del café. ${ }^{16}$

La urbanización en Colombia no fue un proceso natural, ni pacifico, ni mucho menos voluntario, fue particularmente un proceso migratorio que llevo a cuestas condiciones paupérrimas. Los éxodos masivos, desplazamientos forzados, campesinos preocupados por sobrevivir y el destierro de campesinos colonos le dan al proceso colombiano unas particularidades. Por lo anterior es irresponsable compararlo con otros procesos de urbanización a nivel latinoamericano, algunos de los cuales se dieron de manera natural y pacífica impulsados por la industrialización. ${ }^{17}$

A manera de conclusión es crucial entender que para 1950 se manifestaron nuevas consecuencias de este fenómeno migratorio, los desplazamientos del campo a la ciudad dieron como resultado la urbanización acelerada en las principales ciudades de Colombia. La economía exportadora, la violencia política, el conflicto agrario y la industrialización sumaron más inestabilidad e incertidumbre para miles de familias desplazadas sin hogar. En el mismo sentido, los censos nacionales indicaron que en 1951 la población total llego a 11.548.172 de los cuales el 39\% vivía en centros urbanos, y luego de 13 años se dio un incremento aun mayor, ya que para 1964 la población urbana alcanzo el 52\% de un total de 17.484 .508 y en 1973 la población total alcanzo los 22.846.000, de los cuales el 59\% vivía en centros urbanos. Esto demuestra que Colombia no solo estaba pasando de ser un país rural a un país urbano, sino además lo estaba haciendo de manera vertiginosa. ${ }^{18}$

\footnotetext{
${ }^{14}$ Ramiro Cardona, "Migración, urbanización y marginalidad, División de estudios de población”, Revista Estudios de Población 5.8 Asociación Colombiana de Facultades de Medicina (1968): 16.

${ }^{15}$ Segundo Bernal, "Algunos aspectos sociológicos de la migración en Colombia", Boletín Bibliográfico de Antropología Americana B.B.A.A. 23.2 Asociación Colombiana de Facultades de Medicina (1973): 51.

${ }^{16}$ Miguel Fornaguera y Ernesto Guhl, "Colombia. Ordenación del territorio en base del epicentro regional", Revista Universidad de Colombia CINEP 5.4 Universidad Nacional de Colombia (1969): 175

${ }^{17}$ Jacques Aprile-Gniset, La ciudad colombiana. Siglo XIX Y siglo XX (Bogotá: Biblioteca Banco Popular, 1992) 554 .

${ }^{18}$ Luis Mauricio Cuervo y Samuel Jaramillo, "La configuración del espacio regional en Colombia”, Revista
} 
El proceso que resulto de esto fue la colonización popular urbana, donde los anteriores colonos pioneros migraron a las ciudades y allí pasaron a ser destechados urbanos con la intención de ocupar terrenos ociosos y reclamar su derecho al suelo urbano. Se generaron grupos urbanos marginales, no solo compuestos por migrantes sino también por familias originarias de la misma ciudad. La periferia en la mayoría de los casos se convirtió en la zona propicia para los destechados: los bajos costos de la tierra, la posibilidad de invadir terrenos con éxito, la incapacidad de integrarse a las dinámicas culturales de la ciudad moderna, hicieron que aparecieran asentamientos espontáneos en las periferias que poco a poco se fueron insertando al espacio urbano. ${ }^{19}$ En Bogotá el proceso de asentamiento de inmigrantes no se dio totalmente en la periferia, ya que la mayoría de familias se dirigían primero a unas viviendas arrendadas o inquilinatos, algunos de los cuales quedaban en la periferia pero también muchos otros ubicados en el centro de la ciudad. ${ }^{20}$

La búsqueda del Estado Colombiano por controlar el desarrollo y crecimiento de la ciudad, le genero retos imposibles de cumplir, el afán de organizar y gestionar la ciudad se manifestó en un desarrollo urbano fragmentado. Por un lado, estaban los esquemas urbanos primitivos que se mostraban en el centro y la periferia de la ciudad, rastros indudables de la tradición agraria. Y, por otro lado, estaba el desarrollo de la ciudad moderna o gran ciudad, con grandes obras de infraestructura, vías pavimentadas, barrios planificados y servicios públicos. Es así como la ciudad de Bogotá y también otras ciudades del país fueron pobladas y urbanizadas de una manera no planificada y desorganizada. Sumado a lo anterior, el precio de compra y renta de tierra en las zonas planificadas de la ciudad se incrementó año tras año, generando traslados de población hacia periferias con una urbanización extensiva, dilatada y no compacta. ${ }^{21}$

La exclusión, las precarias condiciones de vida, la carencia de servicios públicos, la falta de oportunidades laborales y la carencia de espacios para vivir, se tradujeron en la construcción autónoma de espacios urbanos y así surgieron los denominados barrios populares. Obreros, artesanos, comerciantes, toderos y asalariaos en general reclamaron su espacio en la ciudad, este proceso de colonización urbana adquirió la característica de proceso popular donde las familias construyeron sus propios barrios y organizaron un movimiento por la vivienda. Pero sus demandas e intentos fueron reprimidos ante la imposibilidad del Estado de ofrecer una solución espacial a las necesidades de la población. Las estrategias de represión fueron, el toque de queda, los programas de contención, programas de control y en general el estado de sitio ejercido por el partido conservador. ${ }^{22}$

\footnotetext{
Universidad de los Andes CEDE 2.9. (1987): 367.

${ }^{19}$ Cardona, "Migración, urbanización y marginalidad".

${ }^{20}$ Georges Vernez, "Traslados residenciales de los inmigrantes de bajos ingresos: El caso de Bogotá, Colombia. Corporación Centro Regional de la Población”, Revista Estudios Regionales de Población 2.8 (1976): 139-169.

${ }^{21}$ Aprile-Gniset, 595.

${ }^{22}$ Fernando Viviescas, "Urbanización y ciudad en Colombia. Una cultura por construir en Colombia", Revista Colombiana de Urbanismo 1.5 Foro Nacional por Colombia (1989): 283.
} 
Alberto Melucci profundizando en este aspecto, donde los movimientos sociales antagónicos adquieren la dimensión de categoría de análisis. Estos tienen componentes de una acción colectiva que cuestionan el control de los recursos fundamentales de una estructura, por ejemplo: la tenencia de la tierra que depende de la estructura económica y política fue ampliamente controvertida y llevo a la acción organizada de poblaciones vulnerables en Colombia. La dimensión del movimiento social debe ser examinada, ya que seguramente está presente en cualquier fenómeno de acción colectiva, donde se explica la confluencia de tres elementos, solidaridad, conflicto y tendencias a romper los límites de uno o varios sistemas a los que está adscrita la sociedad. ${ }^{23}$

La acción colectiva de este grupo no emergió naturalmente de la existencia de un antagonismo estructural, el sentido y la existencia de la misma son producto de una construcción compleja que se desarrolló a partir de un conflicto central, el cual al ser detallado y explorado muestra la lucha por la vivienda como único fin último. ${ }^{24}$ Los asentamientos de tierras y la acción colectiva barrial fueron objeto de estudio desde una perspectiva diferente a la totalizante, lo que hizo necesaria una nueva denominación. Como estos grupos buscaban renovación en las prácticas políticas tradicionales, se movilizaban buscando una democracia participativa, buscaban potenciar la capacidad de acción de la sociedad sobre sí misma y sus prácticas eran autónomas sin tener un carácter antagónico como el que se exploró ampliamente con el movimiento obrero, se estudiaron desde su evolución, acción colectiva y formas de asociación para finalmente entender su fuerte impacto en el plano simbólico y cultural. ${ }^{25}$

El desarrollo del concepto de la privación relativa explica por qué los destechados llegaron a este movimiento social. La desigualad evidente en relaciones de poder, recursos económicos y estatus, los motivó a la movilización por la demanda común de vivienda. Las malas condiciones y la pobreza hacen a las personas más propensas a rebelarse, si no se ve una mejora constante de las condiciones especialmente económicas, se da un giro, y en ese punto, las personas se unirán a los movimientos sociales que demandan reivindicaciones. ${ }^{26}$ Por otra parte, los individuos eligen racionalmente apoyar la movilización y estratégicamente las personas eligen un curso de acción que maximice su utilidad poniendo en una balanza los costos y beneficios para definir su participación. Aparece entonces la acción colectiva donde los individuos racionales se benefician de su adquisición y participan activamente del movimiento. ${ }^{27}$ En el contexto de esta investigación, la inmensa mayoría de personas tenían solo algunos enseres de poco valor, por eso no había mucho temor a la pérdida de estas posesiones. Por otro lado, si la movilización y toma de tierra daba resultado se beneficiarían de una vivienda propia, lo que se tradujo en fortalecimiento a la elección

\footnotetext{
${ }^{23}$ Alfredo Melucci, Movimienti di rivolta. Teorie e forme dell'azione collettiva (a cura di) (Milán: Etas, 1976) 56-78.

${ }^{24}$ Luis Restrepo, "Movimientos sociales, la democracia y el socialismo”, Análisis Político.05 (1988):12-34.

${ }^{25}$ Aníbal Viguera, "Movimientos sociales y lucha de clases conflicto social”, Conflicto Social.04 (2009): 1-20.

${ }^{26}$ Ted Gurr, Why Men Rebel, Fortieth (Tallahassee: Anniversary Edition, Florida State University, 1970) 14.

${ }^{27}$ Mancur Olson, The Logic of Collective Action, Public Goods and Theory of Groups (Massachusetts: printed in Harvard University, 1965) 60.
} 
racional de apoyo al movimiento social. Además, la movilización de recursos se da al interior del movimiento social para alcanzar sus objetivos, pero debe tener la tipología de cinco recursos: materiales, morales, social-organizacionales, humanos y culturales. El movimiento Provivienda desarrolló un fondo común para la autoconstrucción de las casas en 1965 y también organizaron un cronograma de trabajo comunal, siendo estos los recursos materiales. ${ }^{28}$ Se desarrollaron relaciones de solidaridad en la toma y ocupación de los terrenos, apoyando siempre los objetivos comunes del movimiento, lo que se puede interpretar como los recursos morales. También se sostuvieron actividades de cooperación con numerosos actores sociales y políticos, generando redes y estrategias organizacionales, lo que hace parte de los recursos social-organizacionales. Y finalmente los recursos humanos y culturales se vieron expresados en voluntarios, personas y líderes que con su experiencia y compresión del contexto ayudaron a dinamizar la acción colectiva. ${ }^{29}$

El movimiento social por la vivienda en Colombia tuvo las características que explica Sidney Tarrow: incertidumbre, desafío y solidaridad. Por medio de la acción colectiva empezaron a combinar recursos que posibilitaron su reivindicación, desafiando a las autoridades, pasando por periodos de profunda incertidumbre, pero por medio de la solidaridad interna y externa mantuvieron su desafío y obtuvieron solución a sus demandas. ${ }^{30}$ La movilización de familias campesinas generó tensiones entre el campo y la ciudad, reconfigurando la densidad urbana de muchos barrios en Bogotá, lo que particularmente sucedió en el barrio Policarpa Salavarrieta, donde se reclamaba el derecho a la ciudad, lo que sería la solución a los problemas del campesinado forzado a desplazarse a los cascos urbanos, donde la ciudad adquirió una categoría diferente a una simple mercancía y pasó a ser un espacio de encuentro, convivencia y disfrute; se creó un tipo de barrio que incluía escenarios deportivos y culturales donde la diferencia respecto al resto de la ciudad eran sus formas de organización y asociación, estas eran autónomas e involucraban a toda la población buscando el bien común. ${ }^{31}$

Cenaprov también era asesorada en materia de educación e investigación sobre problemas de la vivienda por el Centro de Estudios e Investigaciones Sociales (CEIS) y a su vez arquitectos, abogados, estudiantes, artistas, incidieron mucho más en su orientación que los teóricos citados anteriormente. De 1966 a 1984 se dio un crecimiento de los estudios sociales que eran presentados en la revista del CEIS donde se retroalimentaban con los centros de investigación nacionales y en la interdisciplinariedad aportada por intelectuales con diversa formación académica. De este proceso salen a relucir algunos nombres como Eduardo Pizarro Leongómez, Medófilo Medina, Álvaro Oviedo, Juan Peláez, Pedro Figueredo, Gonzalo Arcila,

\footnotetext{
${ }^{28}$ AHP, Fondo MP, Sección Registro Etapa 01 Cenaprov, t. 096, f. 58v.

${ }^{29}$ David Snow, Social Movements: Reading son Their Emergence, Mobilization, and Dynamics (Portland: Roxbury Pub Co., 1997) 22.

${ }^{30}$ Sidney Tarrow, El Poder en Movimiento: Los movimientos Sociales, la acción colectiva y la política (Madrid: Ed. Cast. Alianza Editorial, S. A., 1994) 107.

${ }^{31}$ Henri Lefebvre, El Derecho a la Ciudad (Pensilvania: Península, 1969) 41.
} 
Sergio Caviedes, Lenin Flóres, entre muchos otros. ${ }^{32}$ El abanico de intereses de estos académicos, permitieron el abordaje interdisciplinar de los problemas sociales desde distintas áreas del conocimiento incluido la problemática por la vivienda. Hubo también cartillas para los cursos básicos de los viviendistas como la escrita por Nicolás Buenaventura, ${ }^{33}$ en la cual se explicaba la función social de Cenaprov. De esta manera, la colonización popular urbana se estableció como un rasgo característico de la fase moderna de la urbanización.

Sin embargo, para el caso de Cenaprov sus afiliados eran aquellas personas víctimas de la violencia, que habían sufrido las consecuencias del desplazamiento forzado y que a causa de lo anterior se recogieron en esta organización social desarrollando la autoconstrucción de sus viviendas. Este fue el punto de encuentro donde la misma población se unió, con el fin de generar iniciativas y acciones que les permitieran acceder y conformar una vivienda digna, mediante una ocupación ilegal del espacio. La magnitud de este fenómeno ha sido bastante significativa en Bogotá, pues desde el año de 1938 hasta 1985, las comunidades más pobres, que representan para este periodo cerca de la mitad de la población, buscaron satisfacer sus necesidades de vivienda mediante la autoconstrucción. ${ }^{34}$

Cenaprov se estableció desde sus comienzos como una organización que pretendía no solo apoyar sino también legalizar las pretensiones de vivienda de la población damnificada por la violencia. Aunque el principal objetivo fue el de organizar a las personas para que pudieran resistir los desalojos, poco a poco se fueron desarrollando actividades normativas y jurídicas, con el fin de que la tierra fuera cedida a los nuevos pobladores. Sin embargo, cuando las entidades oficiales se negaban a ceder las tierras por vía legal, se apoyaba a las personas sin vivienda para que realizaran el proceso de ocupación directa y por la fuerza. ${ }^{35}$ De esta forma, se puede decir que el apoyo de Cenaprov a las familias que buscaban el acceso a una vivienda, mediante la autoconstrucción y los procesos de invasión, se desarrolló en varias fases, pues se les prestó asesoría legal y normativa, y también se les brindó ayuda para que se pudieran organizar mejor, con el fin de desarrollar la ocupación directa y evitar los desalojos.

Para la década de 1960, las acciones promovidas por Cenaprov para apoyar a las personas que no tenían vivienda a que ocuparan algún lote o terreno baldío en

\footnotetext{
${ }^{32}$ Héctor Bermúdez, Nicolás Buenaventura Alder 1918-2008 (Cali: Universidad del Valle, 2012) 44.

${ }^{33}$ Nicolás Buenaventura pertenecía a un grupo de intelectuales marxistas que afiliados al Partido Comunista Colombiano reflexionaron sobre la situación del país a través de innumerables investigaciones, en 1970 llega a Bogotá con la idea de impulsar un grupo de investigadores, lo que concluyó el ciclo del CIM (Centro de Investigaciones Marxistas) fundado en el Valle del Cauca y se creó el Centro de Investigaciones Sociales (CEIS), en el barrio Santa Fe, con personería jurídica N. 3358 del 25 de agosto de 1970. La revista Estudios Marxistas se siguió publicando, ahora bajo el sello de CEIS, y con intelectuales radicados en Bogotá. Véase: Nicolás Buenaventura, Cartilla de Educación Básica Provivienda (Bogotá: CENAPROV, 1981) 119.

${ }^{34}$ Samuel Jaramillo, Organización popular y desarrollo urbano de Bogotá (Bogotá: Universidad Externado de Colombia, 1997) 31.

${ }^{35}$ Francisco Hernández, "El Sindicalismo en Colombia: Implicaciones Sociales y Políticas" (Tesis pregrado, Universidad Javeriana, Bogotá, 2004) 45.
} 
espacios urbanos, se desarrollaban por medio de un proceso planificado. Los pasos implementados en este tipo de planes, eran: elaborar un plan detallado con las personas que pretendían ocupar un lote, analizar y conocer previamente el terreno, diseñar planos para ubicar las casetas, abarcando la mayor cantidad posible de terreno, planificar los tiempos de operativos relámpagos, en donde cada quien tenía una función que debía estar sincronizada con la de los demás, establecer reglamentos que debían firmar cada uno de los futuros ocupantes, con el fin de prevenir desacuerdos o disputas sobre el terreno que iba a ser ocupado. ${ }^{36}$

Pero además de ello, Cenaprov ayudó a generar lazos afectivos entre los habitantes y a mejorar considerablemente sus niveles de autoestima, pues comprendían que hacían parte de un grupo, que tenían una comunidad a la cual servir y por la cual luchar. En síntesis, Cenaprov se llegó a convertir en una organización fundamental para liderar la organización de grupos de personas y de comunidades que decidían ocupar las tierras en varios sitios de la ciudad, ante la necesidad impuesta por una situación social y económica precaria. No obstante, se movilizaron cientos de familias que no hacían parte de su estructura y generaron una acción colectiva en torno a una reivindicación común, demostrando la capacidad y el poder social del movimiento; lo que se vio reflejado en los intentos de ocupaciones a los terrenos que más tarde sería el barrio Policarpa Salavarrieta. ${ }^{37}$

Después de hacer este recorrido teórico a continuación se describirán los principales resultados hallados en el curso de esta investigación, empezando con el análisis documental de fuentes primarias y secundarias, contrastándolo con los resultados ya sistematizados de las entrevistas realizadas y finalmente caracterizando la población del barrio.

\section{Población que conformo el barrio Policarpa Salavarrieta, fundación y desarrollo de la organización social en Bogotá}

Se expondrá a continuación la información encontrada en las entrevistas previamente sistematizadas para su análisis. Las entrevistas realizadas por esta investigación sirven para esclarecer la hipótesis sobre la violencia como responsable de la toma del barrio, las mismas tuvieron el objetivo de clarificar cuatro aspectos importantes: establecer el lugar de procedencia de las familias fundadoras del barrio, determinar el tiempo trascurrido desde que llegaron a Bogotá, cuánto tardó su traslado al barrio Policarpa Salavarrieta y conocer cuántas familias fundadoras trabajaron en la organización social del barrio. Se encontró una relación entre el tiempo que tardaron las familias en llegar al barrio ya estando en la ciudad de Bogotá, y el nacimiento de un nuevo movimiento social. Finalmente, se analizó la posterior expansión hacia nuevos territorios, al conocer cuántas de estas familias fundadoras trabajaban en la organización social del barrio.

${ }^{36}$ María Elvira Naranjo, "Provivienda: protagonista de la colonización popular en Colombia", Historia y Memoria.9 (2014): 1-31.

${ }^{37}$ William Gamson, The Strategy of Social Protest (Wadsworth, Belmont, California: Editorial Dorsey PR, 1990) 32. 
Teniendo en cuenta el lugar de procedencia de las familias que realizaron la toma de tierra en la manzana de los fundadores del barrio Policarpa Salavarrieta, podemos afirmar que 12 familias eran procedentes del departamento de Cundinamarca, 11 familias del departamento del Tolima, 9 familias del departamento de Boyacá y 18 familias eran de otros departamentos. De las entrevistas concluimos que Cundinamarca, Tolima y Boyacá fueron los tres departamentos de origen de las familias fundadoras que aportaron el $65 \%$ de personas a la toma de tierra del barrio, estas familias constituyeron la primera manzana del barrio Policarpa Salavarrieta entre 1961 y 1962.

Figura 1. Lugar de procedencia de la familia, 2017, Bogotá.

\section{Lugar de procedencia de la familia}

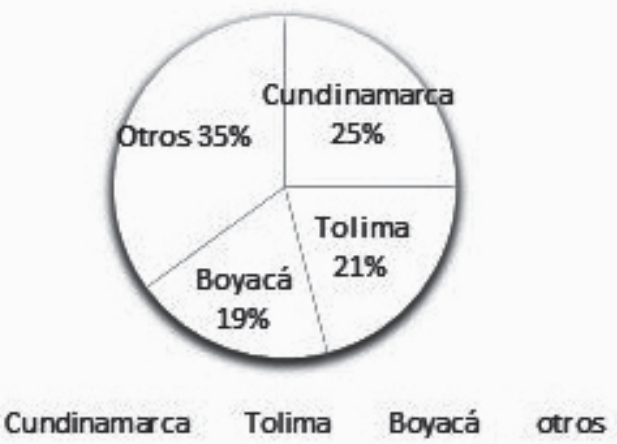

Tabla 1. Lugar de procedencia de la familia, 2017, Bogotá.

\begin{tabular}{|c|c|c|}
\hline Cundinamarca & $25 \%$ & 12 familias \\
\hline Tolima & $21 \%$ & 11 familias \\
\hline Boyacá & $19 \%$ & 9 familias \\
\hline Otros & $35 \%$ & 18 familias \\
\hline Total & $100 \%$ & 50 familias \\
\hline
\end{tabular}

Fuente: producto del proyecto de investigación dirigido por PH. D German Mejía Pavony, de la Escuela de ciencias sociales de la Pontificia Universidad Javeriana al estudiante de maestría en historia de la UPTC Leandro Sánchez en el año 2017.

Ahora contrastando la muestra de esta investigación con el censo realizado por la Universidad Nacional en 1967 en el barrio, se llegó a la conclusión de que el lugar de nacimiento de los jefes de familia coincidía con los lugares de procedencia de las familias del barrio. Cundinamarca, Tolima y Boyacá seguían en los primeros lugares, como lo muestra la siguiente tabla. 
Tabla 2. Lugar de nacimiento del jefe de familia, 1967, Bogotá.

Lugar de nacimiento del Jefe de Familia

\begin{tabular}{lrrlrrr}
\hline Departamento & N9 & $\%$ & Zona & N9 & $\%$ \\
\hline Cundinamarca & 151 & 25.0 & Urbana & 460 & 79.6 \\
Tolima & 128 & 21.2 & Rural & 118 & 20.4 \\
Boyacá & 110 & 19.0 & Total informantes & 578 & 100.0 \\
Santanderes & 57 & 9.4 & Nota: Informó el $87.0 \%$ del total. \\
Caldas (antigua) & 55 & 9.1 & & & \\
Bogota & 44 & 7.3 & & & \\
Otros & 54 & 9.0 & & & \\
\multicolumn{1}{l}{ Total informantes } & 604 & 100.0 & & & \\
Nota: Informó el $90.8 \%$ & del total. & & & \\
\hline
\end{tabular}

Fuente: Centro de Estudios Demográficos de la Universidad Nacional y la División de Estudios de Población de la Asociación Colombiana de Facultades de Medicina, (Archivo Central Histórico de la U. N), Bogotá 1967, por Ramiro Cardona.

Por otra parte, el análisis documental dio como resultado una mejor ilustración de estos desplazamientos hacia las principales ciudades del país. Se encontraron numerosos documentos que ilustran sobre los estragos de la violencia partidista, estos eran informes de la Secretaría de Agricultura del Tolima realizados en $1959 .{ }^{38}$ Dichos informes fueron los primeros en cuantificar las víctimas y las pérdidas materiales, y en describir las modalidades del despojo de tierras entre 1949 y 1957. La persistencia de prácticas violentas tenía una finalidad no solo política sino también económica. Con base en una encuesta aplicada a una muestra estadística de 400 damnificados, los autores de dicho informe estimaron los costos en capital humano que dejó la violencia. En primer lugar, estimaron 16.219 muertos entre 1949 y 1957, sin incluir los muertos a causa de fuerzas regulares del Ejército, ni en masacres colectivas, que generalmente eran abandonados como animales, o arrojados a ríos y precipicios. En segundo lugar, cuantificaron que 321.621 personas (es decir, el 42.6\% de la población del Tolima) sufrieron el exilio en forma permanente o transitoria. En tercer lugar, encontraron que 40.176 propiedades, es decir el $42.82 \%$ del total, pertenecientes a 32.400 propietarios, habían sido abandonadas transitoria o permanentemente. El 46\% de estas tierras fueron abandonadas entre 1955 y 1956. A su vez, los investigadores advirtieron que la estrategia empleada en la violencia era la misma, tanto si se ejercía con fines políticos como económicos: actos de terror contra las personas y sus bienes, que concluyen inexorablemente en un éxodo colectivo. Logrando este resultado, el paso siguiente es mantener latente el terror, para hacer desistir a las víctimas de presuntos o reales propósitos de reintegrarse a la propiedad abandonada. No es explicable de otra manera el empeño sostenido, y aparentemente ilógico, de destruir

\footnotetext{
${ }^{38}$ Archivo Secretaria de Agricultura de la Gobernación del Tolima. Fondo Informes oficiales, núm. 62, Sección agricultura 1959, t. 20, f. 31v.
} 
casas e instalaciones. Los autores del informe calcularon que durante ese periodo se quemaron 34.304 casas, y observaron que en la destrucción de casas e instalaciones intervinieron no solo elementos civiles, sino también las fuerzas regulares en las campañas represivas y en las operaciones denominadas "tierra arrasada" que realizaron en diversas zonas. Otro informe también precisa que la estimación de las pérdidas materiales en dinero no incluyó lo referente al lucro cesante que han sufrido los exiliados campesinos, representado en valores correspondientes a la renta de la tierra más el valor de las cosechas por concepto de cultivos permanentes como el café. ${ }^{39}$ Los investigadores de la Secretaría de Agricultura del Tolima establecieron que los más afectados económicamente fueron los propietarios rurales $33.8 \%$, los jornaleros $28.17 \%$ y quienes se dedicaban a oficios domésticos $15.49 \%$; el porcentaje restante correspondía a propietarios urbanos, comerciantes y dueños de semovientes.

Podemos concluir que las familias campesinas huyeron del departamento del Tolima a los centros urbanos en desarrollo entre 1948 y 1953, siendo estos los años más intensos de la violencia. Los departamentos más afectados por los homicidios fueron el antiguo Caldas 24.6\%, Tolima 17.2\%, Antioquia 14.5\%, Norte de Santander 11.6\%, Santander $10.7 \%$ y Valle del Cauca $7.3 \%$. En cuanto al abandono o despojo de tierras, se calcula que los propietarios de tierras perdieron 393.648 parcelas, y que los departamentos más afectados fueron Valle del Cauca, Tolima, Cundinamarca, Norte de Santander y antiguo Caldas. Colombia experimentó un fenómeno masivo de desplazamiento forzado entre 1948 y 1966, donde 193.017 personas resultaron muertas, producto de la violencia partidista. ${ }^{40}$

Al analizar los resultados de las entrevistas realizadas en 2017, considerando en un segundo momento los resultados del censo realizado por la Universidad Nacional en 1966, teniendo en cuenta también el análisis documental de los informes de la Secretaria de Agricultura del Tolima en 1959 y finalmente contrastando algunas fuentes secundarias que explican los estragos de la violencia entre 1948 - 1953, los primeros resultados de esta investigación confirmaron la hipótesis inicial. Los departamentos de Cundinamarca, Tolima, Santander y Caldas aportaron el 64.7\% de la población total del barrio Policarpa Salavarrieta para 1966, siendo esta población desplazada por la violencia rural la que llegó a la ciudad de Bogotá, pasando por otras zonas urbanas del país antes de llegar a la capital.

La violencia fue la principal motivación para que estas familias se trasladaran a la capital del país, pero no fue la única, también la pobreza rural, la falta de empleo, el anhelo de vivienda propia, entre muchas otras causas contribuyeron a movilizar estas personas del campo a la ciudad. Es importante aclarar también, que al rastrear los vestigios de la violencia en estos departamentos por medio de las familias fundadoras del barrio Policarpa se pudo analizar su relación con el movimiento por la vivienda, teniendo

\footnotetext{
${ }^{39}$ Los campesinos fueron sistemáticamente desplazados de sus parcelas, para ser entregadas a los grandes terratenientes, así es entonces como se pasa de la finca minifundista del campesino colono, a la finca latifundista del terrateniente, Véase: Aprile-Gniset, 100.

${ }^{40}$ Paul Oquist, Violencia, conflicto y política en Colombia (Bogotá: Banco Popular, 1978) 322.
} 
presente las limitaciones que conllevaron analizar particularmente un barrio a través del gigantesco proceso de desplazamiento en el país después del asesinato de Jorge Eliécer Gaitán en 1948, proceso que es altamente complejo y profundamente diverso.

Tabla 3. Lugar donde vivió por última vez el jefe de familia antes de venir a Bogotá, 1967, Bogotá.

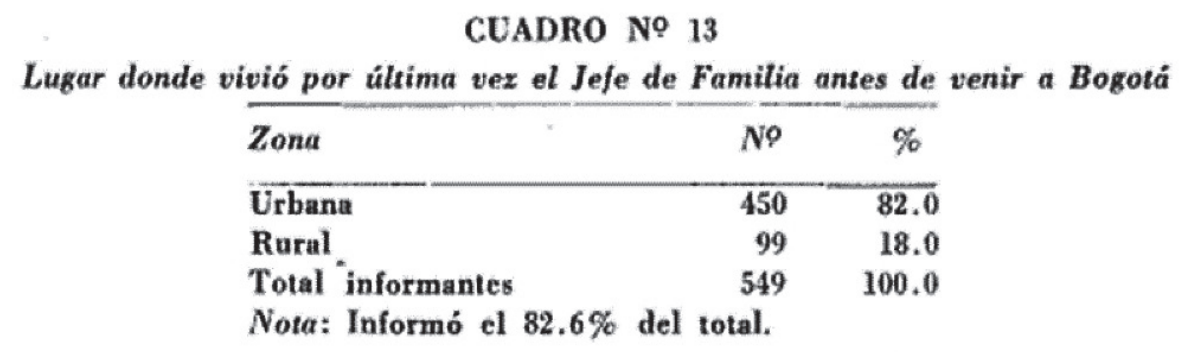

Fuente: Centro de Estudios Demográficos de la Universidad Nacional y la División de Estudios de Población de la Asociación Colombiana de Facultades de Medicina, (Archivo Central Histórico de la U. N), Bogotá 1967, por Ramiro Cardona.

Los 50 entrevistados de la manzana de los fundadores respondieron la pregunta: cuánto tiempo tardaron en llegar al barrio Policarpa ya estando en la ciudad de Bogotá, 16 familias llegaron directamente, lo que corresponde al 33\%, 19 familias tardaron menos de un año, lo que corresponde al 37\%, 9 familias llegaron de uno a menos de dos años, lo que corresponde a $18 \%$ y finalmente 6 familias llegaron de dos a menos de cuatro años, lo que corresponde a $12 \%$.

Figura 2. Tiempo que tardó en trasladarse al barrio Policarpa Salavarrieta desde su llegada a Bogotá, 2017, Bogotá.

\section{Tiempo que tardó en trasladarse al barrio Policarpa Salavarrieta desde su llegada a Bogotá}

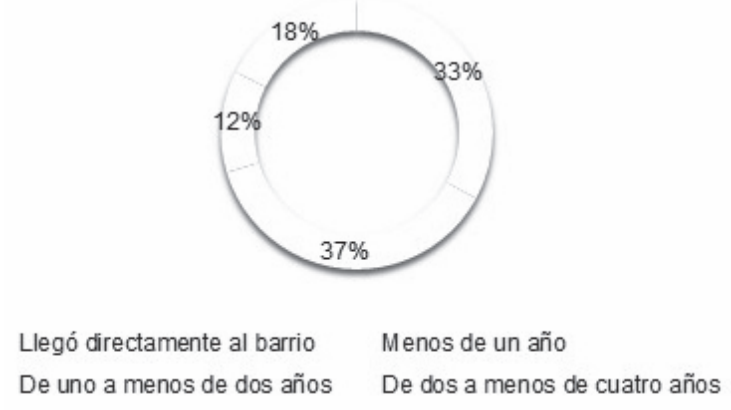

Fuente: producto del proyecto de investigación dirigido por PH. D German Mejia Pavony, de la Escuela de ciencias sociales de la Pontificia Universidad Javeriana al estudiante de maestría en historia de la UPTC Leandro Sanchez en el año 2017. 
Estas familias se enteraron del proceso de toma de tierra por medio de las asambleas populares, ${ }^{41}$ llevadas a cabo por los centros de inquilinos los cuales actuaban de forma planificada y no reaccionaban espontáneamente, desarrollaron un proceso para afiliar a las personas y se sumaron a Cenaprov en calidad de afiliados o asociados. ${ }^{42}$ Los resultados demuestran que existió una relación entre la llegada directa de la población desplazada al barrio Policarpa Salavarrieta y el nacimiento del nuevo movimiento social, ya que el $33 \%$ de los fundadores llegaron directamente a los terrenos y un $37 \%$ llegó en un periodo menor a un año. Así mismo, se afiliaron y participaron de forma activa en la organización del movimiento donde las experiencias vividas en el barrio Policarpa Salavarrieta serían los cimientos de su plan de acción inmediato y futuro. ${ }^{43}$

Las condiciones precarias llevaron al movimiento social de los destechados a organizarse para ocupar terrenos, sus condiciones vulnerables solo se traducían en la esperanza de una oportunidad para ocupar los terrenos que Cenaprov identificaba para las tomas organizadas. Su situación anterior a estas oportunidades de invasión era difícil, ya que vivían hacinados en inquilinatos miserables. ${ }^{44}$ En respuesta, se crearon los Centros de Inquilinos de Provivienda; pero aún la problemática era muy aguda y necesitaban formar a las personas para organizar la toma de los terrenos. Así que desde el Partido Comunista algunos militantes brindaron formación política dejando claros a los socios los objetivos de Provivienda, educaron sobre el problema de la vivienda, sus soluciones, y capacitaron para participar en las acciones colectivas de ocupación de predios. ${ }^{45}$ Estos centros tenían también la tarea de encontrar predios cercanos a las ciudades en donde se pudieran ubicar las familias que no tenían vivienda y promover la afiliación de inquilinos, donde por ejemplo el centro de inquilinos número cinco llegó a tener más de tres mil afiliados. ${ }^{46}$

El período más activo y significativo de los movimientos populares que buscaban ejercer el derecho a la ciudad de habitantes urbanos sin techo o con una infraestructura deficiente, fue la década de 1960. La organización más sobresaliente en ese movimiento es la Central Nacional Provivienda, orientada por el Partido Comunista PCC y representada por acciones directas y organizadas. El barrio Policarpa Salavarrieta siendo la primera experiencia exitosa planificada, sirvió para consolidar

\footnotetext{
${ }^{41}$ Archivo AHP, Fondo MP, Sección Registro Etapa 01 Cenaprov, t. 102, f 03v.

42 Cenaprov estuvo compuesta por dueños de fincas cafeteras que se construían en terrenos baldíos, y que eran despojados a causa de los hechos que sucedían a finales de la década de 1950 y comienzo de 1960, marcados por la violencia bipartidista. A partir del apoyo de Cenaprov, estas personas iniciaron un proceso de colonización de ejidos y terrenos municipales en centros poblados. Véase María Elvira Naranjo Botero, "Provivienda: protagonista de la colonización popular en Colombia", Historia y Memoria.09 (2014): 37.

${ }^{43}$ Naranjo Botero, "Provivienda" 1-31.

${ }^{44}$ Los primeros barrios colonizados en los espacios urbanos carecían de las condiciones básicas para vivir de manera digna, no fueron producto de acuerdos con el Estado ni de un pacto pacífico. Los nuevos habitantes tuvieron que juntarse, con el fin de generar el desarrollo de acciones colectivas como marchas, bloqueos y pedreas, por medio de las cuales trataban de resistirse al desalojo. También se organizaban para reunir fondos a través de eventos como festivales, bazares y mingas, que además ayudaban a promover lazos de hermandad y unidad entre las personas. Véase: Naranjo Botero, "Provivienda" 41.

${ }^{45}$ Archivo AHP, Fondo MP, Sección Registro Etapa 01 Cenaprov, t. 109, f. 06v.

${ }^{46}$ Archivo AHP, Fondo MP, Sección Registro Etapa 01 Cenaprov, t. 71, f. 28v.
} 
la organización social de Cenaprov y para expandirse posteriormente por Bogotá y diferentes lugares del país. ${ }^{47}$

Es importante nombrar a dos personajes que contribuyeron en el terreno político a la consolidación de este movimiento, ellos fueron Julio Rincón y Alfonso Barberena, en la revisión documental se encontró que Barberena fue personero municipal de Cali donde realizó acciones decididas de apoyo a los destechados, y cuando se desempeñó como congresista logró la aprobación de la Ley 41 de 1948, también conocida como Ley Barberena sobre los terrenos ejidales, por la cual se estableció la imprescriptibilidad de los ejidos o tierras comunales alrededor de los centros urbanos. ${ }^{48}$ Por otra parte, Pedro Salas y Álvaro Rodríguez dirigieron la invasión del barrio Policarpa Salavarrieta desde adentro, ya que poseían experiencia como defensores de los destechados, pues pertenecían desde antes a las recién creadas comisiones de Cenaprov que intentaban por todo el país consolidar el movimiento social por la vivienda. Su trayectoria los vincula a Mario Upegui, con quien Salas ya había trabajado en La Dorada, Caldas y su afiliación política los relaciona con los sindicatos de trabajadores, el movimiento obrero, la corriente Gaitanista liberal y el Partido Comunista Colombiano, PCC. ${ }^{49}$

Después de realizar una aproximación al movimiento social por la vivienda, es del interés de este artículo reconstruir genealógicamente parte de la historia de las familias, desde la primera generación fundadora del barrio hasta su segunda generación, lo anterior con el fin de encontrar la relación entre los nuevos barrios fundados por este movimiento social y las familias fundadoras del barrio Policarpa Salavarrieta. El resultado de este proceso de reconstrucción, fue descubrir que muchos de los hijos de los fundadores de la manzana 01 del barrio Policarpa Salavarrieta fueron líderes de otros procesos de toma de tierra en Bogotá. Por ejemplo: Empera Salas hija de Pedro Antonio Salas junto con Saúl Baquero fundaron el centro de inquilinos número diez, el cual fundo el barrio Julio Rincón en $1970 .^{50}$ José Rafael Sánchez y Camilo Upegui hijos de José Efraín Sánchez y Mario Upegui, ayudaron a Vladimir Escobar y a Mario Upegui en la toma de 35 familias sin techo de unos terrenos continuos al barrio San Mateo, donde después de una ardua lucha se funda el barrio El Porvenir en 1978. ${ }^{51}$

Después de consolidado el barrio Policarpa Salavarrieta en 1970, Cenaprov a través de la acción colectiva se movilizó apoyando a otras familias sin techo y fundó nuevos barrios con la ayuda de sus afiliados. En el siguiente cuadro se presenta la lista de fundadores del barrio Policarpa Salavarrieta relacionándolos con los procesos que apoyaron en otros barrios, los cuales llevaron las banderas de Cenaprov.

\footnotetext{
47 Alfonso Torres, La ciudad en la sombra. Barrios y luchas populares en Bogotá, 1950-1977 (Bogotá: Universidad Piloto de Colombia 2013) 142.

${ }^{48}$ Archivo AHP, Fondo MP, Sección Registro Etapa 01 Cenaprov, t. 121, f. 09v.

${ }^{49}$ Torres, 131-146.

${ }^{50}$ Archivo AACD, Fondo PS, Sección Actas de Registro. t. 203, f. v89.

${ }^{51}$ Leandro Sánchez, "Cenaprov y la construcción de barrios en Bogotá de 1959 a 1979: los casos de Policarpa Salavarrieta y Julio Rincón” (Tesis, Maestría en Historia, Universidad Pedagógica y Tecnológica de Colombia, 2017) 73-80.
} 
Aproximación al barrio Policarpa Salavarrieta por medio de la organización social...

Tabla 4. Listado de fundadores, 2017, Bogotá.

\begin{tabular}{|c|c|c|}
\hline \multicolumn{3}{|c|}{ Lista de fundadores del barrio Policarpa Salavarrieta, manzana 01} \\
\hline Fundadores & Hijos & $\begin{array}{c}\text { Proceso barrial que } \\
\text { apoyaron }\end{array}$ \\
\hline $\begin{array}{l}\text { 1. José Medina y } \\
\text { Ana Isabel Garzón } \\
\text { de Medina }\end{array}$ & $\begin{array}{l}\text { Rosa Medina, Graciela Medina, } \\
\text { Mercedes Medina, Rafael } \\
\text { Medina, Raúl Medina, Gloria } \\
\text { Medina, Dora Medina, Mirian } \\
\text { Medina. } \\
\end{array}$ & Nuevo Chile y Julio Rincón. \\
\hline $\begin{array}{l}\text { 2. Efraín Sánchez y } \\
\text { María Nieves Quito }\end{array}$ & $\begin{array}{l}\text { Ismael Sánchez, Hipólito } \\
\text { Sánchez Carmenza Sánchez, } \\
\text { Rafael Sánchez. }\end{array}$ & Nuevo Chile y Julio Rincón. \\
\hline 3. María Lucia Ríos & $\begin{array}{l}\text { Enrique Berbecí Ríos, Elsa } \\
\text { María Berbecí Ríos. }\end{array}$ & El Porvenir \\
\hline 4. María Antonia & Rafaela Antonia & Julio Rincón \\
\hline 5. Teresa Guerrero & Miguel Guerrero, Rita Guerrero. & $\begin{array}{l}\text { El Porvenir, Las Colinas y } \\
\text { Salvador Allende. }\end{array}$ \\
\hline $\begin{array}{l}\text { 6. José Pompilio } \\
\text { Martínez y María } \\
\text { del Carmen Acosta }\end{array}$ & $\begin{array}{c}\text { Isabel Martínez, Ana Martínez, } \\
\text { Liocelina Martínez, Mercedes } \\
\text { Martínez. }\end{array}$ & Bravo Páez y El Porvenir. \\
\hline 7. Isabel de Mate & $\begin{array}{l}\text { Yaneth de Mate, Armando de } \\
\text { Mate German de Mate. }\end{array}$ & $\begin{array}{c}\text { José María Vargas Vila y } \\
\text { Bravo Páez. }\end{array}$ \\
\hline $\begin{array}{l}\text { 8. Juan de Jesús } \\
\text { Triana y Ana Rosa } \\
\text { Cruz de Triana }\end{array}$ & $\begin{array}{l}\text { José Triana, Tulia Triana, María } \\
\text { A. Triana, Margarita Triana, } \\
\text { Alfonso Triana, Clemencia } \\
\text { Triana, Silvia Triana, Cesar A. } \\
\text { Triana. } \\
\end{array}$ & $\begin{array}{c}\text { Las Colinas y Salvador } \\
\text { Allende }\end{array}$ \\
\hline $\begin{array}{l}\text { 9. Álvaro Rozo y } \\
\text { Rosa Elcira Vargas }\end{array}$ & $\begin{array}{c}\text { Alcira Rozo, Jorge Rozo, Susana } \\
\text { Rozo, Álvaro Rozo, Flor Rozo, } \\
\text { Lucero Rozo, Gabriel Rozo, } \\
\text { Rolan } \\
\text { Rozo. }\end{array}$ & El Porvenir y Nuevo Chile \\
\hline $\begin{array}{l}\text { 10.Aureliano } \\
\text { Lozano y María } \\
\text { Araujo de Lozano }\end{array}$ & $\begin{array}{l}\text { Luz M. Lozano, Marco A. } \\
\text { Lozano, Luis E. Lozano, Gerardo } \\
\text { Lozano, Yolanda Lozano, } \\
\text { Mary Lozano, Luz D. Lozano, } \\
\text { Angélica Lozano. }\end{array}$ & $\begin{array}{c}\text { Las Colinas y Salvador } \\
\text { Allende }\end{array}$ \\
\hline $\begin{array}{l}\text { 11. José Bello y } \\
\text { Margarita Quintero }\end{array}$ & $\begin{array}{ll}\text { Flor } & \text { Bello, Alba Bello, } \\
\text { Yolanda } & \text { Bello, Luis Bello. }\end{array}$ & Las Colinas \\
\hline $\begin{array}{l}\text { 12. Gilberto Ayala y } \\
\text { Marlen Quintero }\end{array}$ & $\begin{array}{l}\text { Fredy Ayala, Yenni Ayala, } \\
\text { Patricia Ayala, Álvaro Ayala. }\end{array}$ & $\begin{array}{c}\text { Las Colinas y Salvador } \\
\text { Allende }\end{array}$ \\
\hline
\end{tabular}


Anuario de Historia Regional y de las Fronteras Vol.23 No.2

\begin{tabular}{|c|c|c|}
\hline 13. Rosa de Cantillo & $\begin{array}{c}\text { Alexander Cantillo, Yolima } \\
\text { Cantillo. }\end{array}$ & Nuevo Chile \\
\hline $\begin{array}{l}\text { 14. Mario Upegui y } \\
\text { Astrid Lozano }\end{array}$ & $\begin{array}{c}\text { Gilberto Upegui, Sandra Upegui, } \\
\text { Judith Upegui, Libia Upegui, } \\
\text { Camilo Upegui. }\end{array}$ & $\begin{array}{c}\text { Pablo Neruda, Julio Rincón, } \\
\text { Nuevo Chile, José María } \\
\text { Vargas Vila, Bravo Páez, } \\
\text { El Porvenir, Luis Alberto } \\
\text { Vega, Camilo Torres, Los } \\
\text { Comuneros, Las Colinas y } \\
\text { Salvador Allende. }\end{array}$ \\
\hline $\begin{array}{l}\text { 15. Luis A. Morales } \\
\text { y Ninfa de Morales }\end{array}$ & Tania Morales, Luis C. Morales. & $\begin{array}{c}\text { Pablo Neruda, Julio Rincón, } \\
\text { Nuevo Chile, José María } \\
\text { Vargas Vila, Bravo Páez, } \\
\text { El Porvenir, Luis Alberto } \\
\text { Vega, Camilo Torres, Los } \\
\text { Comuneros, Las Colinas y } \\
\text { Salvador Allende. }\end{array}$ \\
\hline $\begin{array}{l}\text { 16. Pedro Antonio } \\
\text { Salas e Isabel de } \\
\text { Salas }\end{array}$ & $\begin{array}{c}\text { Empera Salas, Dalia Salas, } \\
\text { Magnolia Salas, Diamela Salas. }\end{array}$ & $\begin{array}{c}\text { Pablo Neruda, Julio Rincón, } \\
\text { Nuevo Chile, José María } \\
\text { Vargas Vila, Bravo Páez, } \\
\text { El Porvenir, Luis Alberto } \\
\text { Vega, Camilo Torres, los } \\
\text { Comuneros, Las Colinas y } \\
\text { Salvador Allende. }\end{array}$ \\
\hline $\begin{array}{l}\text { 17. Jesús Mariano } \\
\text { Lozano e Isabel } \\
\text { Lozano Cárdenas }\end{array}$ & $\begin{array}{c}\text { Stella Lozano, Marlen Lozano, } \\
\text { Aurora } \begin{array}{c}\text { Lozano, Samuel } \\
\text { Lozano. }\end{array}\end{array}$ & $\begin{array}{c}\text { Los Comuneros y Camilo } \\
\text { Torres }\end{array}$ \\
\hline $\begin{array}{l}\text { 18. Alfonso Araujo } \\
\text { y Graciela Ruiz de } \\
\text { Araujo }\end{array}$ & Omar Araujo, Ruth Araujo. & El Porvenir \\
\hline $\begin{array}{l}\text { 19. Pedro Antonio } \\
\text { López y Gloria } \\
\text { María Inés } \\
\text { Rodríguez }\end{array}$ & $\begin{array}{l}\text { Álvaro López, Gloria López, } \\
\text { Javier López, Tito López, } \\
\text { Luis A. López, José W. López. }\end{array}$ & Nuevo Chile \\
\hline 20. Alcira Sandoval & $\begin{array}{c}\text { María C. Sandoval, Alejandra } \\
\text { Sandoval. }\end{array}$ & $\begin{array}{c}\text { Las Colinas y Salvador } \\
\text { Allende }\end{array}$ \\
\hline $\begin{array}{l}\text { 21. Gonzalo Pinto y } \\
\text { María Mora }\end{array}$ & $\begin{array}{c}\text { Alejandro Pinto, Juan C. Pinto } \\
\text { Liliana Pinto. }\end{array}$ & El Porvenir y Nuevo Chile \\
\hline $\begin{array}{l}\text { 22. Alejandrina } \\
\text { Morales }\end{array}$ & $\begin{array}{l}\text { Blanca Morales, Eduardo } \\
\text { Morales, Alonso Morales. }\end{array}$ & $\begin{array}{l}\text { El Porvenir, Las Colinas y } \\
\text { Salvador Allende. }\end{array}$ \\
\hline $\begin{array}{l}\text { 23. José Antonio } \\
\text { Silva y Luciana E. } \\
\text { Rojas de Silva }\end{array}$ & Jairo A. Silva, Omar Silva. & $\begin{array}{l}\text { Las Colinas Y Salvador } \\
\text { Allende }\end{array}$ \\
\hline
\end{tabular}


Aproximación al barrio Policarpa Salavarrieta por medio de la organización social...

\begin{tabular}{|c|c|c|}
\hline $\begin{array}{c}\text { 24. Reinaldo } \\
\text { Sánchez y Flor } \\
\text { Suarez }\end{array}$ & $\begin{array}{c}\text { Alberto Suarez, Humberto } \\
\text { Suarez, Gilberto Suarez, Flor } \\
\text { Suarez, Carmenza Suarez. }\end{array}$ & Nuevo Chile \\
\hline $\begin{array}{c}\text { 25. Luis A. Pinto y } \\
\text { Mercedes Sandoval }\end{array}$ & $\begin{array}{c}\text { Pedro Pinto, Jorge Pinto, Sofía } \\
\text { Pinto, Hugo Pinto, Rodolfo } \\
\text { Pinto, Rances Pinto, Wilson } \\
\text { Pinto, Óscar Pinto, Esperanza } \\
\text { Pinto, Chávela Pinto. }\end{array}$ & Julio Rincón \\
\hline $\begin{array}{c}\text { 26. Martin Villalba } \\
\text { y Raquel Álvarez }\end{array}$ & $\begin{array}{c}\text { Aurora Villalba, Gloria Villalba, } \\
\text { Gloria Villalba, Marina Villalba, } \\
\text { Gladys Villalba, Alirio Villalba. }\end{array}$ & $\begin{array}{c}\text { Las Colinas y Salvador } \\
\text { Allende. }\end{array}$ \\
\hline
\end{tabular}

Fuente: producto del proyecto de investigación dirigido por PH. D German Mejía Pavony, de la Escuela de ciencias sociales de la Pontificia Universidad Javeriana al estudiante de maestría en historia de la UPTC Leandro Sánchez en el año 2017.

Las comisiones que auxiliaban en sus fases más críticas a los nuevos barrios se desprendían de la Junta Directiva y esta a su vez de la Asamblea General. La Junta Directiva estaba integrada por: presidente, vicepresidente, secretario, tesorero, fiscal y cinco vocales, ellos debían hacer cumplir las determinaciones de la Asamblea General impulsando planes y programas de la organización. Las comisiones por sector y las comisiones auxiliares eran las encargadas de impulsar las decisiones que se tomaran en la Asamblea General y en la Junta Directiva, así como de desarrollar paralelamente sus actividades como sector. Cada comisión estaba integrada por un responsable, un secretario, un tesorero y finalmente un responsable de solidaridad.

También existía la posibilidad que se crearan comisiones especiales para asuntos concretos, como comisiones especiales de mejoras, higiene, cultura, deporte, energía, acueducto, control, disciplina, educación, etc. Dichas comisiones variaban dependiendo de las actividades encomendadas por la Junta Directiva. Todos los barrios se organizaron con la orientación de Cenaprov y siguieron cada una de sus recomendaciones sobre los procesos de Asamblea General, Junta Directiva y Comisiones, así fue posible ayudar en los momentos difíciles a los nuevos barrios por medio de las comisiones de solidaridad que tenían ya consolidadas los barrios más antiguos. ${ }^{52}$

Los procesos de los barrios Nuevo Chile, Julio Rincón y El Porvenir fueron los más apoyados por los fundadores del barrio Policarpa Salavarrieta, un $42 \%$ de los entrevistados se identificó con estos procesos barriales. Por otra parte, los barrios Las Colinas y Salvador Allende fueron barrios que se fundaron inmediatamente después del barrio Policarpa Salavarrieta y el 26\% de los entrevistados manifestaron que ayudaron en la toma, fundación y desarrollo. El 10\% apoyó los procesos de los barrios Los Comuneros y Camilo Torres, un 22\% apoyó los procesos de los barrios Pablo Neruda, José María Vargas Vila, Bravo Páez y Luis Alberto Vega. Los asentamientos más grandes y de mayor impacto de los anteriores mencionados, ubicados en diferentes partes de la ciudad se caracterizaron por ser procesos de colonización urbana

\footnotetext{
${ }^{52}$ Sánchez, "Cenaprov” 125.
} 
espontáneos. ${ }^{53}$ Con estas nuevas victorias en diferentes barrios tomó más fuerza la lucha por la tierra en Bogotá, donde se expandió y consolidó un nuevo movimiento social en Colombia.

Figura 3. Barrios que apoyaron los fundadores del barrio Policarpa Salavarrieta, 2017, Bogotá.

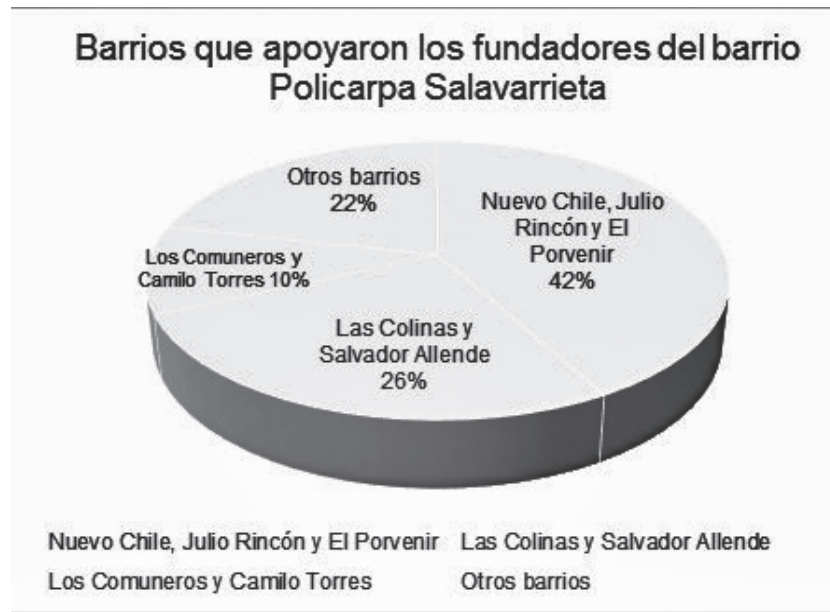

Fuente: producto del proyecto de investigación dirigido por PH. D German Mejía Pavony, de la Escuela de ciencias sociales de la Pontificia Universidad Javeriana al estudiante de maestría en historia de la UPTC Leandro Sánchez en el año 2017.

\section{Presentación de resultados y caracterización de la población fundadora del barrio Policarpa Salavarrieta}

El barrio Policarpa Salavarrieta estuvo formado en sus inicios por diferentes grupos de la sociedad, estos incluyeron: desplazados, trabajadores, población vulnerable, sindicalistas; hombres y mujeres que tenían una problemática en común, la falta de vivienda. ${ }^{54}$ El 53.9\% de la población del barrio correspondía a niños menores de 15 años, el $41.9 \%$ tenían entre 15 y 49 años y solo el $4.2 \%$ tenían 50 años o más. Existían en el barrio 104 mujeres por cada 100 hombres. Solamente en los grupos de edades de 10-19 años y de 40-49 años había más hombres que mujeres. El total de hombres en el barrio era de 1.763 y las mujeres eran 1.836, eso quiere decir que para 1966 el barrio Policarpa Salavarrieta contaba con una población de 3.599 habitantes. Por otra parte, si analizamos detenidamente lo anterior, la primera conclusión importante es que el $55.3 \%$ de la población del barrio era dependiente, estos eran los menores de 15 años y los mayores de 60 años.

\footnotetext{
${ }^{53}$ Sánchez, "Cenaprov" 125.

${ }^{54}$ Carlos Arango, Lucha por la vivienda en Colombia (Bogotá: ECOE, 1986) 54.
} 
Aproximación al barrio Policarpa Salavarrieta por medio de la organización social...

Tabla 5. Población del barrio Policarpa Salavarrieta por grupos, edad y sexo, 1967, Bogotá.

\section{CUADRO 1}

Población del Barrio "Policarpa Salavarrieta" por grupos, edad y sexo.

\begin{tabular}{lrrrrrr}
\hline $\begin{array}{c}\text { Grupos de } \\
\text { Edad } \\
\text { (En años) }\end{array}$ & No. & $\%$ & No. & $\%$ & No. & $\%$ \\
\hline $0-4$ & 376 & 21.3 & 397 & 21.6 & 773 & 21.5 \\
$5-9$ & 345 & 19.6 & 409 & 22.3 & 754 & 21.0 \\
$10-14$ & 260 & 14.7 & 150 & 8.2 & 410 & 11.4 \\
$15-19$ & 220 & 12.5 & 202 & 11.0 & 422 & 11.7 \\
$20-24$ & 102 & 5.8 & 158 & 8.6 & 260 & 7.2 \\
$25-29$ & 100 & 5.7 & 135 & 7.4 & 235 & 6.5 \\
$30-34$ & 102 & 5.8 & 116 & 6.3 & 218 & 6.1 \\
$35-39$ & 95 & 5.4 & 96 & 5.2 & 191 & 5.3 \\
$40-49$ & 97 & 5.5 & 88 & 4.8 & 185 & 5.1 \\
50 y más & 66 & 3.7 & 85 & 4.6 & 1515 & 4.2 \\
Total & 1.763 & 100.0 & 1.836 & 100.0 & 3.599 & 100.0 \\
\hline
\end{tabular}

Fuente: Centro de Estudios Demográficos de la Universidad Nacional y la División de Estudios de Población de la Asociación Colombiana de Facultades de Medicina. Archivo Central Histórico de la U. N, Bogotá 1967, por Ramiro Cardona.

Las familias estaban compuestas en su mayoría por 3 miembros que representaban el $28.3 \%$, seguidas de las familias compuestas por 4 y 5 miembros que representaban el $27.9 \%$ y finalmente las familias de 6 y 7 miembros representaban los tres grupos más altos de conformación familiar, esta última con un $19.1 \%$.

Tabla 6. Número de personas que forman la familia, 1967, Bogotá.

\section{CUADRO 2}

Número de personas que forman la familia.

\begin{tabular}{lccc}
\hline Personas & Familias & $\%$ & $\%$ Acumulado \\
\hline 1 & 15 & 2.4 & 2.4 \\
2 & 42 & 6.7 & 9.1 \\
3 & 177 & 28.3 & 37.5 \\
$4-5$ & 174 & 27.9 & 65.4 \\
$6-7$ & 119 & 19.1 & 84.5 \\
$8-9$ & 63 & 10.1 & 94.6 \\
$10-11$ & 22 & 3.5 & 98.1 \\
$12-13$ & 12 & 1.9 & 100.0 \\
& & 100.0 & 100.0 \\
\hline
\end{tabular}

Fuente: Centro de Estudios Demográficos de la Universidad Nacional y la División de Estudios de Población de la Asociación Colombiana de Facultades de Medicina. Archivo Central Histórico de la U. N, Bogotá 1967, por Ramiro Cardona. 
La composición familiar según el parentesco nos muestra un grado de modernización respecto a lo que se denomina familia extensa, ya que solo el 14\% de las familias las componían además de padres e hijos otros familiares. También si se compara el número de familias únicamente con madre e hijos tenemos un resultado alto del $15.6 \%$ respecto a las familias compuestas por padre e hijos que tan solo eran el $2.1 \%$.

Tabla 7. Composición familiar según parentesco, 1967, Bogotá.

\section{CUADRO 4}

Composición familiar según parentesco.

\begin{tabular}{lcr}
\hline Parentesco & No. de familias & $\%$ \\
\hline Padre, madre e hijos & 416 & 66.9 \\
Padre e Hijos & 13 & 2.1 \\
Madre e hijos & 97 & 15.6 \\
Hijos solos & 7 & 1.1 \\
Otro tipo de familiar & 89 & 14.3 \\
Total informantes & 622 & 100.0 \\
\hline
\end{tabular}

Fuente: Centro de Estudios Demográficos de la Universidad Nacional y la División de Estudios de Población de la Asociación Colombiana de Facultades de Medicina, (Archivo Central Histórico de la U. N), Bogotá 1967, por Ramiro Cardona.

Respecto a la edad del jefe de la familia se encontró que la mayoría estaban entre 30 y 34 años, los cuales correspondían a un $22.6 \%$ de la población del barrio. Más abajo en la tabla, el $21.7 \%$ tenía de 40 a 49 años y el 20.2\% tenían de 35 a 39 años, siendo estos los tres rangos de edad más significativos de los jefes de familia. Lo anterior nos indica que existió un alto porcentaje respecto a los jefes de hogar que tenían menos de 30 años, los cuales correspondían a un $23 \%$.

Tabla 8. Edad del jefe de familia, 1967, Bogotá.

\section{CUADRO 5}

Edad del Jefe de Familia

\begin{tabular}{lccc}
\hline Grupos de edad & No. & $\%$ & \% Acumulado \\
\hline Menos de 25 años & 38 & 6.4 & 6.4 \\
$25-29$ & 98 & 16.5 & 22.9 \\
$30-34$ & 134 & 22.6 & 45.5 \\
$35-39$ & 120 & 20.2 & 65.7 \\
$40-49$ & 129 & 21.7 & 87.5 \\
$50-59$ & 53 & 8.9 & 96.3 \\
60 y más años & 22 & 3.7 & 100.0 \\
Total informantes & 594 & 100.0 & \\
\hline
\end{tabular}

Nota: No informó el $10,7 \%$.

Fuente: Centro de Estudios Demográficos de la Universidad Nacional y la División de Estudios de Población de la Asociación Colombiana de Facultades de Medicina. Archivo Central Histórico de la U. N, Bogotá 1967, por Ramiro Cardona. 
Aproximación al barrio Policarpa Salavarrieta por medio de la organización social...

Respecto a la educación del jefe de la familia el porcentaje más alto lo ocupaban las personas que habían estudiado hasta cuarto de primaria con un $60.5 \%$ y solo un $27.4 \%$ de las personas habían superado el umbral de la educación básica.

Tabla 9. Educación del jefe de familia, 1967, Bogotá.

CUADRO 6

Educación del Jefe de Familia

\begin{tabular}{lrrc}
\hline Años de estudio & No. & $\%$ & $\%$ Acumulado \\
\hline Ninguno & 59 & 12.1 & 12.1 \\
$1-2$ primaria & 140 & 28.6 & 40.7 \\
$3-4$ primaria & 156 & 31.9 & 72.6 \\
Completa & 94 & 19.2 & 91.8 \\
Secundaria, universitaria, especial & 40 & 8.2 & 100.0 \\
Total informantes & 489 & 100.0 & \\
\hline
\end{tabular}

Fuente: Centro de Estudios Demográficos de la Universidad Nacional y la División de Estudios de Población de la Asociación Colombiana de Facultades de Medicina. Archivo Central Histórico de la U. N, Bogotá 1967, por Ramiro Cardona.

Los padres eran los principales dadores del sustento en los hogares, de cada 100 hogares en el barrio 77 dependían de su trabajo; un punto de reflexión importante es que el $63.4 \%$ se sostenían con el trabajo de alguno de los padres cabeza de hogar.

Tabla 10. Personas que trabajan en la familia, 1967, Bogotá.

CUADRO No. ?

Personas que trabajan en la familia

\begin{tabular}{lrc}
\hline Parentesco & No. & $\%$ \\
\hline Solo el padre o la madro & 390 & 63.4 \\
El padre y la madre & 86 & 14.0 \\
Los padres y algunos hijos & 106 & 17.2 \\
Solo los hijos & 31 & 5.1 \\
Nadie & 2 & 0.3 \\
Total de informantes & 615 & 100.0 \\
\hline
\end{tabular}

Fuente: Centro de Estudios Demográficos de la Universidad Nacional y la División de Estudios de Población de la Asociación Colombiana de Facultades de Medicina. Archivo Central Histórico de la U. N, Bogotá 1967, por Ramiro Cardona.

La ocupación de los jefes de familia se podía representar en dos grandes categorías: los empleados y los trabajadores por cuenta propia, donde se presentaba un amplio número de personas que trabajaban de forma independiente, lo que correspondía al $55.3 \%$ de los habitantes del barrio. Respecto a las características del trabajo, los dos grupos más grandes estaban ubicados en los que tenían un trabajo fijo de tiempo completo con $51.5 \%$ y los que tenían un trabajo ocasional de medio tiempo con $26.3 \%$. Por otro lado, a pesar de que el $55.5 \%$ de los jefes de hogar tenían un empleo fijo, era preocupante el alto porcentaje de familias que tenían un ingreso inestable, debido a los empleos ocasionales de los jefes de familia. 
Tabla 11. Características de la ocupación del jefe de la familia, 1967, Bogotá.

CUADRO No. 8

Caracteristicas de la ocupación del Jefe de Familia

\begin{tabular}{lcrlrrr}
\hline $\begin{array}{l}\text { Clase de } \\
\text { Ocupación }\end{array}$ & NP & $\%$ & $\begin{array}{l}\text { Caracteristica } \\
\text { del } \text { Trabajo }\end{array}$ & No & $\%$ \\
\hline Empleado & 234 & 44.7 & Fijo de tiempo completo & 258 & 51.5 \\
Cuenta propia & 290 & 55.3 & Fijo de medio tiempo & 20 & 4.0 \\
$\quad$ Total & 524 & 100.0 & Ocasional tiempo completo & 91 & 18.2 \\
& & & Ocasional medio tiempo & 132 & 26.3 \\
& & Total & 501 & 100.0 \\
& & &
\end{tabular}

Nota: Informó el $78.8 \%$ del
total.

Fuente: Centro de Estudios Demográficos de la Universidad Nacional y la División de Estudios de Población de la Asociación Colombiana de Facultades de Medicina. Archivo Central Histórico de la U. N, Bogotá 1967, por Ramiro Cardona.

Desde el año 1961 a 1966 se habían constituido algunos negocios en el barrio, los cuales eran de diferentes tipos, entre estos estaban: tiendas, talleres, negocio de animales, cultivos, fábrica y otros. El $24.4 \%$ de la población del barrio poseía un negocio y de estas personas el $27.1 \%$ tenían una tienda, el $36.8 \%$ tenía un taller, lo que constituía las dos formas más importantes de tenencia de un negocio en el barrio Policarpa Salavarrieta en la década de los años sesenta.

Tabla 12. Tenencia de negocio en el barrio, 1967, Bogotá.

\section{CUADRO NQ 9}

Tenencia de negocio en el barrio

\begin{tabular}{|c|c|c|c|c|c|}
\hline Tenencia & NP & $\%$ & Tipo de negocio & No & $\%$ \\
\hline Tiene & 144 & 24.4 & Tienda & 39 & 27.1 \\
\hline No tiene & 445 & 75.6 & Taller & 53 & 36.8 \\
\hline \multirow{2}{*}{ Total informantes } & 589 & 100.0 & Animales & 3 & 2.1 \\
\hline & & & Cultivo8 & 15 & 10.4 \\
\hline \multirow{3}{*}{$\begin{aligned} \text { Nota: } & \text { No informó el } \\
& \text { total. }\end{aligned}$} & $11.4 \%$ & del & Fábrica & 5 & 3.5 \\
\hline & & & Otros & 29 & 20.1 \\
\hline & & & Total & 144 & 100.0 \\
\hline
\end{tabular}

Fuente: Centro de Estudios Demográficos de la Universidad Nacional y la División de Estudios de Población de la Asociación Colombiana de Facultades de Medicina. Archivo Central Histórico de la U. N, Bogotá 1967, por Ramiro Cardona.

Las personas que trabajaban en el barrio eran el $25.6 \%$ y el otro $74.4 \%$ no trabajaban en el barrio, lo que demuestra las dificultades que tuvieron que pasar para sobrellevar una toma de tierra y además buscar su sustento diario fuera del barrio. A su vez, es importante resaltar que el $15.0 \%$ de las personas que trabajaban lo hacían con la organización del barrio. 
Aproximación al barrio Policarpa Salavarrieta por medio de la organización social...

Tabla 13. Trabajo remunerado en el barrio, 1967, Bogotá.

CUADRO No 10

Trabajo remunerado en el barrio

\begin{tabular}{|c|c|c|c|c|c|}
\hline $\begin{array}{l}\text { Trabaja con el } \\
\text { barrio }\end{array}$ & No. & $\%$ & $\begin{array}{l}\text { Persona que tiene } \\
\text { el trabajo }\end{array}$ & Ne & $\%$ \\
\hline Si & 133 & 25.6 & El padre & 61 & 50.0 \\
\hline No & 387 & 74.4 & La madre & 42 & 34.4 \\
\hline \multirow[t]{3}{*}{ Total informantes } & 520 & 100.0 & Un hijo & 12 & 9.8 \\
\hline & & & Otro familiar & 7 & 5.8 \\
\hline & & & Total informantes & 122 & 100.0 \\
\hline Entidad con & quien & abaja & No & $\%$ & \\
\hline \multirow{2}{*}{\multicolumn{3}{|c|}{$\begin{array}{l}\text { Particular } \\
\text { Con la organización del barrio }\end{array}$}} & 110 & 82.7 & \\
\hline & & & 20 & 15.0 & \\
\hline \multicolumn{3}{|c|}{ Otros } & 3 & 2.3 & \\
\hline \multicolumn{3}{|c|}{ Total informantes } & 133 & 100.0 & \\
\hline
\end{tabular}

Fuente: Centro de Estudios Demográficos de la Universidad Nacional y la División de Estudios de Población de la Asociación Colombiana de Facultades de Medicina. Archivo Central Histórico de la U. N, Bogotá 1967, por Ramiro Cardona.

Las familias en su mayoría no tenían propiedades fuera del barrio, el 92.2\% dependían únicamente del éxito en la toma del barrio Policarpa, mientras que el 4.8\% tenía algún otro tipo de propiedad fuera del barrio. Algunos talleres, tiendas, cultivos y propiedades de otra naturaleza hacían parte del inventario del tipo de propiedades, donde queda comprobado que ninguno tenía una casa fuera del barrio.

Tabla 14. Propiedades fuera del barrio, 1967, Bogotá.

CUADRO NO 11

Propiedades fuera del barrio

\begin{tabular}{lrrlrrr}
\hline Tiene & N & $\%$ & Tipo de propieded & N & $\%$ \\
\hline Si & 27 & 4.8 & Taller & 12 & 44.5 \\
No & 538 & 95.2 & Tienda & 4 & 14.8 \\
\multicolumn{2}{l}{ Total informantes } & 565 & 100.0 & Fábrica & 1 & 3.7 \\
Nota: Informó el 85\%. & & Cultivos & 3 & 11.1 \\
& & & Otros & 7 & 25.9 \\
& & & & Total & 27 & 100.0
\end{tabular}

Fuente: Centro de Estudios Demográficos de la Universidad Nacional y la División de Estudios de Población de la Asociación Colombiana de Facultades de Medicina. Archivo Central Histórico de la U. N, Bogotá 1967, por Ramiro Cardona. 
A pesar de conocer la información relacionada con la población del barrio Policarpa Salavarrieta referente al censo realizado en 1967 por la Universidad Nacional, es importante aclarar que existen limitaciones, como lo son la inexistencia de estudios o censos detallados sobre el barrio para las décadas siguientes. No obstante, la población fue creciendo y cambiando en dinámicas, para 1970 el panorama era diferente marcado por otro tipo de necesidades y problemáticas como la legalización de los servicios públicos. En este sentido, los datos expuestos anteriormente van encaminados a realizar una aproximación al proceso definitivo que les permitió a estas familias consolidar su permanencia en el territorio, por lo anterior se resalta en esta investigación el momento decisivo en la toma del territorio, una fecha popularmente conocida por los habitantes del barrio como el "viernes santo sangriento" de 1966.

\section{Conclusiones}

A continuación, se expondrán algunos elementos centrales de la investigación a manera de conclusiones. En primer lugar, el recorrido histórico sobre el proceso de toma de tierra en el barrio Policarpa Salavarrieta nos aproxima a considerar que la acción colectiva fue la base de la movilización y la disputa popular. También este recorrido sugiere que las formas de resistencia fueron variadas y se desarrollaron a partir de la población desplazada que llegó a los terrenos de la capital del país sin ninguna opción de vivienda, pasando por periodos de represión, enfrentaron la falta de apoyo estatal y vieron líderes de su movimiento desaparecer, pero a pesar de las precarias condiciones, el movimiento social se consolidó y garantizó una vivienda propia para cientos de familias. Sus actividades siempre estuvieron asociadas a la construcción de relaciones de confianza, reciprocidad y solidaridad.

En segundo lugar, la aproximación teórica permitió advertir que el movimiento por la vivienda a través de una campaña coyuntural masificó sus reivindicaciones y a través de la acción colectiva les dio una solución. Además, generó una organización social estructurada a partir de los grupos sociales que perseguían sus mismas reivindicaciones. Utilizó redes sociales, tradiciones y solidaridades que sostuvieron sus actividades, junto con la cooperación de numerosos actores sociales y políticos, lo que se expresó en la dimensión política por medio de representantes. El movimiento social por la vivienda resolvió el problema de la invisibilización a sus demandas, respondiendo a las oportunidades políticas a través del uso de formas conocidas de acción colectiva, como la movilización planificada a nuevos territorios, actividades legítimas y campañas populares.

El tercer elemento es el análisis de los resultados, se obtuvieron resultados cualitativos por parte de la revisión de documentos, testimonios, escritos y entrevistas, pero a su vez se obtuvieron resultados estadísticos que se cuantificaron con mediciones que permitieron dar nociones más exactas de los procesos del barrio Policarpa Salavarrieta. Además, se contrastó toda la información presentada en unos resultados generales, con la intención de analizar integralmente la muestra elegida por esta investigación y confrontar los datos obtenidos con la información de las demás fuentes, así podemos afirmar que se hizo un acercamiento riguroso a la población fundadora del barrio 
Aproximación al barrio Policarpa Salavarrieta por medio de la organización social...

Policarpa Salavarrieta y por lo tanto se realizó una interpretación confiable sobre su papel protagónico en el movimiento por la vivienda.

Finalmente, con la esperanza de hacer una contribución significativa al análisis del devenir del movimiento por la vivienda en Colombia con enfoque histórico, se realizó esta modesta aproximación. Es importante manifestar que el barrio Policarpa Salavarrieta es el caso de la lucha por la vida, la dignidad y la supervivencia. En la ciudad, la valentía, el compromiso y la tenacidad de sus habitantes se convirtió en un referente de la lucha por la vivienda, en un ejemplo que seguirían muchas otras poblaciones que participaron de procesos de invasión similares, siempre buscando mejorar su situación negativa ante la violencia, la falta de apoyo y de oportunidades. Es hoy ejemplo de acción social organizada por los derechos a la ciudad. Ubicado, de oriente a occidente, entre las carreras $10^{\mathrm{a}}$ y 13 , y de norte a sur entre las calles $1^{\mathrm{a}}$ y $5^{\mathrm{a}}$ sur, es también una muestra de autogestión y pujanza.

\section{Bibliografía}

\section{Fuentes primarias}

\section{Fuentes de archivo}

Archivo Acción Comunal Distrital, (AACD). Policarpa Salavarrieta (PS), Actas de Registro. tt. 191, 203; Sección Barrios, Fondo Distrital, caja 18, documentos 10-23.

Archivo Histórico de Provivienda (AHP), Municipios de Provivienda (MP), Fondo actas de registro. tt.087, 092, 094, 021. 096,109, 071, 028, 121; Sección Colecciones, Fondo Cenaprov, caja 3, 4,7, documentos 18-113.

Archivo Secretaria de Agricultura de la Gobernación del Tolima (ISA), Gobernación del Tolima (GT). Sección agricultura, Fondo Violencia en el Tolima/año1959. Documentos 7-14.

\section{Entrevistas}

Araujo Ruiz, Omar, Ruth, entrevistados por Leandro Andrés Sánchez. Bogotá, 27 de enero de 2017.

Ayala Quintero, Fredy, Yenni, Ayala, Ayala, entrevistados por Leandro Andrés Sánchez. Bogotá, 16 de enero de 2017.

Bello, Flor, Alba, Yolanda, Luis, entrevistados por Leandro Andrés Sánchez. Bogotá, 16 de enero de 2017.

Cantillo Alexander, Yolima, entrevistados por Leandro Andrés Sánchez. Bogotá, 18 de enero de 2017. 
Guerrero, Miguel, Rita, entrevistados por Leandro Andrés Sánchez. Bogotá, 19 de diciembre de 2016 .

López Rodríguez, Álvaro, Gloria, Javier, Tito, Luis, José W., entrevistados por Leandro Andrés Sánchez. Bogotá, 28 de enero de 2017.

Lozano Cárdenas, Stella, Marlen, Aurora, Samuel, entrevistados por Leandro Andrés Sánchez. Bogotá, 24 de enero de 2017.

Lozano, Luz, Marco, Luis, Gerardo, Yolanda, Mary, Luz, Angélica, entrevistados por Leandro Andrés Sánchez. Bogotá, 15 de enero de 2017.

Martínez, Ana, Liocelina, Mercedes, entrevistadas por Leandro Andrés Sánchez. Bogotá, 20 de diciembre de 2016.

Mate, Yaneth, Armando, German, entrevistados por Leandro Andrés Sánchez. Bogotá, 10 de enero de 2017.

Medina Garzón, José, Ana Isabel, Rosa, Graciela, Mercedes, Rafael, Raúl, Gloria, Dora, Mirian, entrevistados por Leandro Andrés Sánchez. Bogotá, 14 de diciembre de 2016.

Morales, Tania, Luis C., entrevistados por Leandro Andrés Sánchez. Bogotá, 22 de enero de 2017.

Pinto Mora, Alejandro, Juan, Liliana, entrevistados por Leandro Andrés Sánchez. Bogotá, 06 de febrero de 2017.

Pinto Sandoval, Pedro, Jorge, Sofía, Hugo, Rodolfo, Rances, Wilson, Óscar, Esperanza, Chávela, entrevistados por Leandro Andrés Sánchez. Bogotá, 11 de febrero de 2017.

Ríos Berbecí, Enrique, Elsa María, entrevistados por Leandro Andrés Sánchez. Bogotá, 17 de diciembre de 2016.

Rozo Vargas, Alcira, Jorge, Susana, Álvaro, Flor, Lucero, Gabriel, Rolan, entrevistados por Leandro Andrés Sánchez. Bogotá, 13 de enero de 2017.

Salas, Empero, Dalia, Magnolia, Diamela, entrevistados por Leandro Andrés Sánchez. Bogotá, 23 de enero de 2017.

Sánchez Quito, Ismael, Hipólito, Rafael, entrevistados por Leandro Andrés Sánchez. Bogotá, 16 de diciembre de 2016.

Sánchez Suarez, Alberto, Humberto, Gilberto, Flor, Carmenza, entrevistados por Leandro Andrés Sánchez. Bogotá, 10 de febrero de 2017. 
Aproximación al barrio Policarpa Salavarrieta por medio de la organización social...

Sandoval, María, Alejandra, entrevistados por Leandro Andrés Sánchez. Bogotá, 04 de febrero de 2017.

Silva Rojas, Jairo, Omar, entrevistados por Leandro Andrés Sánchez. Bogotá, 07 de febrero de 2017.

Triana, Ana Rosa, José, Tulia, María, Margarita, Alfonso, Clemencia, Silvia, Cesar A, entrevistados por Leandro Andrés Sánchez. Bogotá, 12 de enero de 2017.

Upegui Lozano, Gilberto, Sandra, Judith, Libia, Camilo, entrevistados por Leandro Andrés Sánchez. Bogotá, 19 de enero de 2017.

Villalba Álvarez, Aurora, Gloria, Marina, Gladys, Alirio, entrevistados por Leandro Andrés Sánchez. Bogotá, 14 de febrero de 2017.

\section{Fuentes secundarias}

\section{Libros}

Aprile-Gniset, Jacques. La Ciudad Colombiana. Bogotá: Banco Popular, 1992.

Arango, Carlos. Lucha por la vivienda en Colombia. Bogotá: ECOE, 1986.

Bermúdez, Héctor. Nicolás Buenaventura Alder 1918-2008. Cali: Universidad del Valle, 2012.

Buenaventura, Nicolás. Cartilla de Educación Básica Provivienda. Bogotá: CENAPROV, 1981.

Gamson, William. The Strategy of Social Protest. Wadsworth, Belmont, California: Editorial Dorsey PR, 1990.

Gurr, Ted. Why Men Rebel, Fortieth. Tallahassee: Anniversary Edition, Florida State University, 1970.

Jaramillo, Samuel. Organización popular y desarrollo urbano de Bogotá. Bogotá: Universidad Externado de Colombia, 1997.

Lefebvre, Henri. El Derecho a la Ciudad. Pensilvania: Península, 1969.

Melucci, Alfredo. Movimienti di rivolta. Teorie e forme dell'azione collettiva (a cura di). Milán: Etas, 1976.

Oquist, Paul. Violencia, conflicto y política en Colombia. Bogotá: Banco Popular, 1978. 
Olson, Mancur. The Logic of Collective Action, Public Goods and Theory of Groups. Massachusetts: printed in Harvard University, 1965.

Palacios, Marco. Entre la legitimidad y la violencia. Colombia 1875-1994. Bogotá: Editorial Norma, 1995.

Snow, David. Social Movements: Reading son Their Emergence, Mobilization, and Dynamics. Portland: Roxbury Pub. Co., 1997.

Tarrow, Sidney. El Poder en Movimiento: Los movimientos Sociales, la acción colectiva y la política. Madrid: Ed. Cast. Alianza Editorial, S. A. 1994.

Touraine, Alain. Critica De la Modernidad. Madrid: Fondo de Cultura Económica de España, 1997.

Torres, Alfonso. La ciudad en la sombra. Barrios y luchas populares en Bogotá, 1950-1977. Bogotá: Universidad Piloto de Colombia, 2013.

\section{Artículos de revista}

Aprile-Gniset, Jacques. Mosquera Gilma. "Dos ensayos sobre la ciudad colombiana". Notas sobre el urbanismo de colonización agraria 1.3 Universidad del Valle (1978): 198-231.

Bernal, Segundo. "Algunos aspectos sociológicos de la migración en Colombia". Boletín Bibliográfico de Antropología Americana B.B.A.A. 23.2 Asociación Colombiana de Facultades de Medicina (1973): 279-459.

Cardona, Ramiro. "Estudio de un Barrio de Invasión". Revista de la Universidad Social Católica de la Salle 1.1 Universidad Católica (1967): 1-20.

Cardona, Ramiro. "Migración, urbanización y marginalidad, División de estudios de población". Revista Estudios de Población 5.8 Asociación Colombiana de Facultades de Medicina (1968): 31-67.

Cuervo, Luis Mauricio. Jaramillo, Samuel. "La configuración del espacio regional en Colombia”. Revista Universidad de los Andes CEDE 2.9 (1987): 40- 62.

Fornaguera, Miguel y Guhl, Ernesto. "Colombia. Ordenación del territorio en base del epicentro regional". Revista Universidad Nacional de Colombia CINEP 5.4 (1969): $52-75$.

Naranjo, María. "Provivienda: protagonista de la colonización popular en Colombia". Historia y Memoria 8.9 (2014): 33-65.

Restrepo, Luis. "Movimientos sociales, la democracia y el socialismo". Análisis Político 2.6 (1988): 1-54 
Aproximación al barrio Policarpa Salavarrieta por medio de la organización social...

Tirado, Álvaro. "Colombia: siglo y medio de bipartidismo". Colombia hoyPerspectivas hacia el siglo XXI 1.1 (1991): 102-130.

Vernez, Georges. "Traslados residenciales de los inmigrantes de bajos ingresos: El caso de Bogotá, Colombia”. Revista Estudios Regionales de Población 2.8 (1976): 139-169.

Viviescas, Fernando. "Urbanización y ciudad en Colombia. Una cultura por construir en Colombia". Revista Colombiana de Urbanismo 1.5 Foro Nacional por Colombia (1989): 26-49.

Viguera, Aníbal. "Movimientos sociales y lucha de clases conflicto social”, Revista Conflicto Social 9.3 (2009): 22-47.

\section{Publicaciones en Internet}

www.semana.com/wfinfoarticulo.aspxldArt22102, 2002 (2018). 